\title{
BISON Fuel Performance Analysis of FeCrAl cladding with updated properties
}

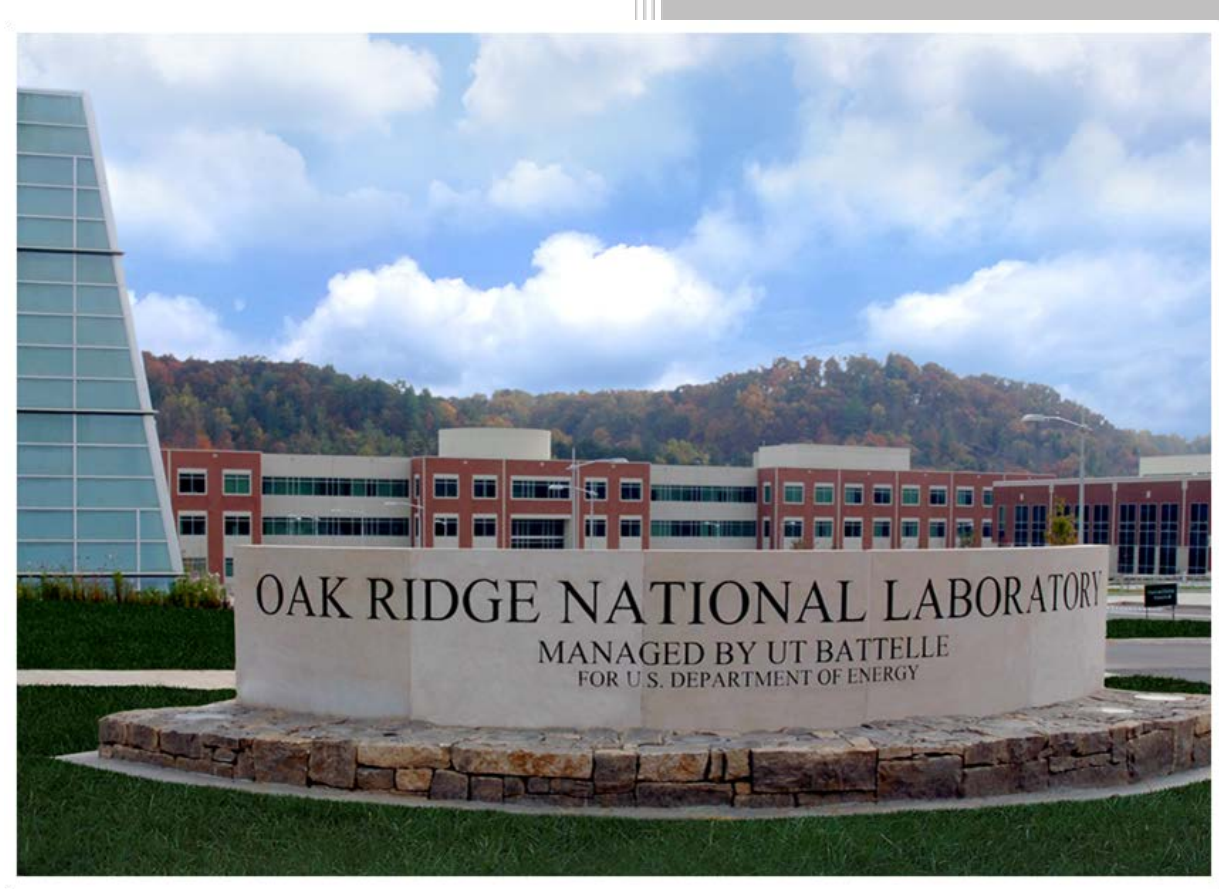

Approved for public release. Distribution is unlimited.
Ryan Sweet Nathan George Kurt Terrani Brian Wirth

August 30, 2016 


\title{
DOCUMENT AVAILABILITY
}

Reports produced after January 1, 1996, are generally available free via US Department of Energy (DOE) SciTech Connect.

Website http://www.osti.gov/scitech/

Reports produced before January 1, 1996, may be purchased by members of the public from the following source:

\author{
National Technical Information Service \\ 5285 Port Royal Road \\ Springfield, VA 22161 \\ Telephone 703-605-6000 (1-800-553-6847) \\ TDD 703-487-4639 \\ Fax 703-605-6900 \\ E-mail info@ntis.gov \\ Website http://www.ntis.gov/help/ordermethods.aspx
}

Reports are available to DOE employees, DOE contractors, Energy Technology Data Exchange representatives, and International Nuclear Information System representatives from the following source:

Office of Scientific and Technical Information

PO Box 62

Oak Ridge, TN 37831

Telephone 865-576-8401

Fax 865-576-5728

E-mail reports@osti.gov

Website http://www.osti.gov/contact.html

This report was prepared as an account of work sponsored by an agency of the United States Government. Neither the United States Government nor any agency thereof, nor any of their employees, makes any warranty, express or implied, or assumes any legal liability or responsibility for the accuracy, completeness, or usefulness of any information, apparatus, product, or process disclosed, or represents that its use would not infringe privately owned rights. Reference herein to any specific commercial product, process, or service by trade name, trademark, manufacturer, or otherwise, does not necessarily constitute or imply its endorsement, recommendation, or favoring by the United States Government or any agency thereof. The views and opinions of authors expressed herein do not necessarily state or reflect those of the United States Government or any agency thereof. 
US DOE Fuel Cycle Research and Development Advanced Fuels Campaign

\title{
BISON FUEL PERFORMANCE ANALYSIS OF FECRAL CLADDING WITH
} UPDATED PROPERTIES

\author{
Ryan Sweet \\ Nathan George \\ Kurt Terrani \\ Brian Wirth
}

Date Published: August 30, 2016

\author{
Prepared by \\ OAK RIDGE NATIONAL LABORATORY \\ Oak Ridge, TN 37831-6283 \\ managed by \\ UT-BATTELLE, LLC \\ for the \\ US DEPARTMENT OF ENERGY \\ under contract DE-AC05-00OR22725
}


INTENTIONALLY BLANK 


\section{CONTENTS}

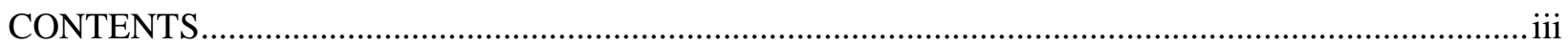

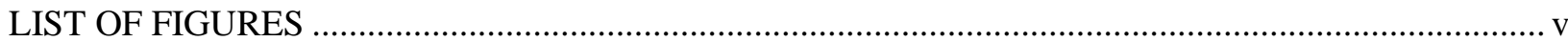

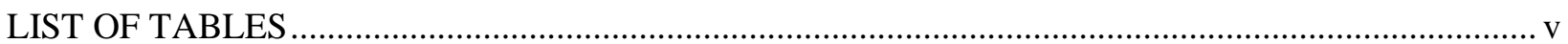

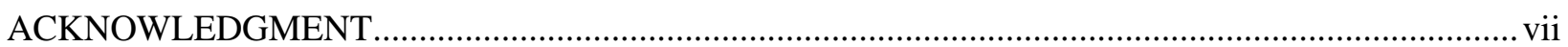

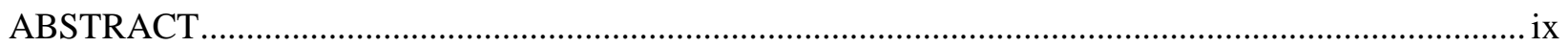

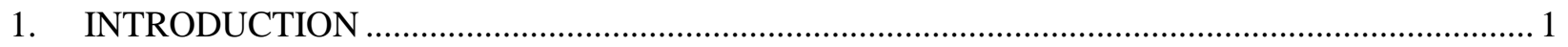

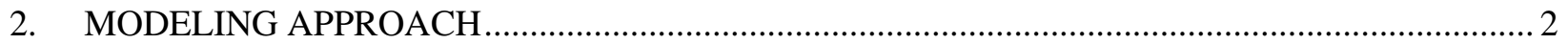

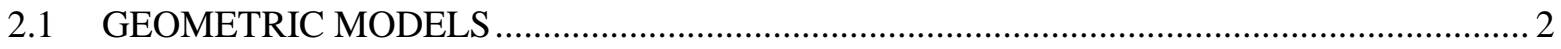

2.2 CONSTITUTIVE AND BEHAVIORAL MODELS ............................................................ 3

2.3 IMPLEMENTATION AND COMPARISON OF CREEP, GROWTH, AND

SWELLING MODELS................................................................................................. 4

2.4 BOUNDARY CONDITIONS AND SIMULATION INPUT PARAMETERS ........................ 7

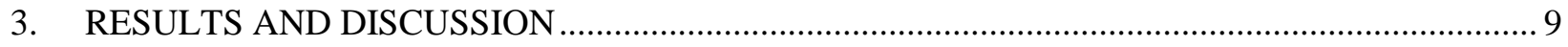

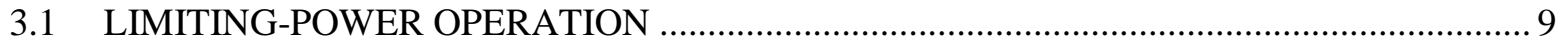

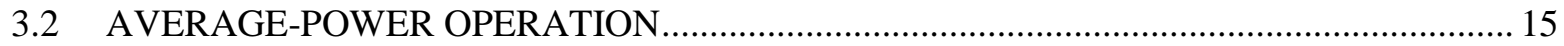

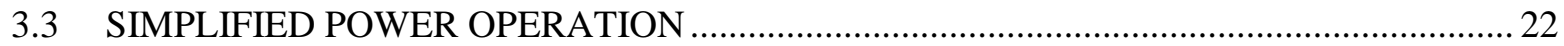

3.4 CLADDING THERMAL AND IRRADIATION CREEP ANALYSIS ................................ 28

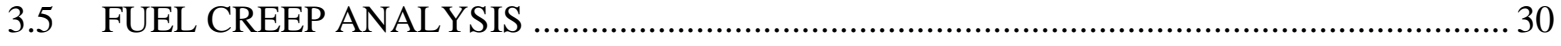

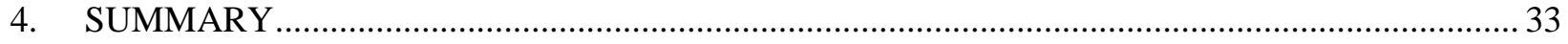

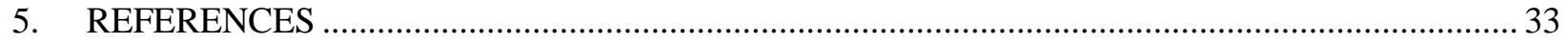


INTENTIONALLY BLANK 


\section{LIST OF FIGURES}

Figure 1. Segment of axisymmetric mesh for $300 \mu \mathrm{m}$ FeCrAl Cladding. ................................................. 3

Figure 2. Irradiation (left) and thermal (right) creep rate comparison for Zircaloy and FeCrAl. .............. 6

Figure 3. Power History and Selected Axial power profiles for Limiting and Average rod

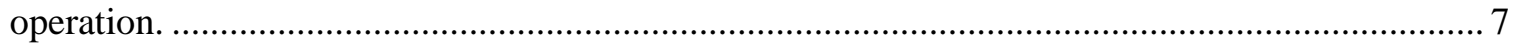

Figure 4. Power history and axial power profile for constant-power rod operation. ............................... 8

Figure 5. Peak and average fuel centerline temperatures during the simulation.................................... 10

Figure 6. Axial elongation and maximum radial displacement of the cladding.................................... 11

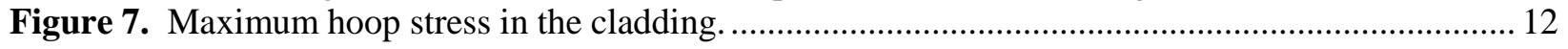

Figure 8. Fission gas generation in the fuel and release to the plenum................................................. 13

Figure 9. Fuel rod internal plenum pressure and gas volume. ............................................................. 14

Figure 10. Peak and average fuel centerline temperatures for average-power operation

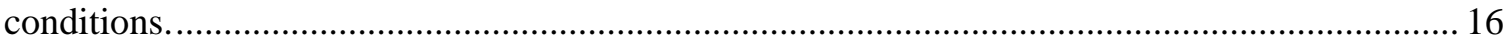

Figure 11. Axial elongation and maximum radial displacement of the cladding................................... 17

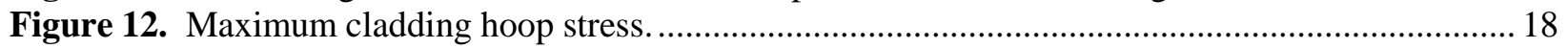

Figure 13. Fission gas generation in the fuel and release to the plenum............................................... 20

Figure 14. Fuel rod internal plenum pressure and plenum volume....................................................... 21

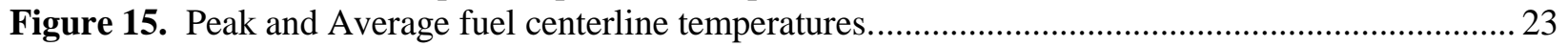

Figure 16. Axial elongation and maximum radial displacement of the cladding.................................... 24

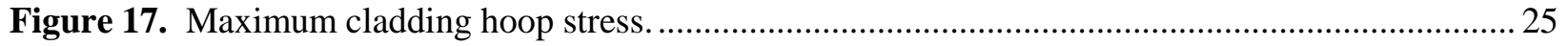

Figure 18. Fission gas generated in the fuel (left) and percent of fission gas released to the fuel

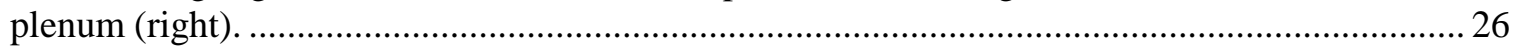

Figure 19. Fuel rod internal plenum pressure and plenum volume..................................................... 27

Figure 20. Contour plots of maximum cladding hoop stress as a function of thermal creep preexponential and activation energy for irradiation creep pre-factor of $.5 \times 10^{-6}$ (left) and .5

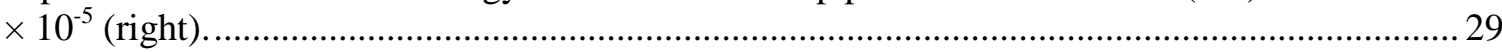

Figure 21. Maximum hoop stress and radial displacement of the fuel over the simulation time.............. 31

Figure 22. Maximum cladding stress and radial displacement of the fuel over the simulation

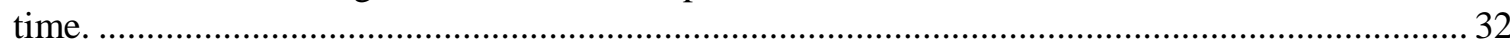

\section{LIST OF TABLES}

Table 1. Fuel geometry specifications for 2D axisymmetric fuel performance analyses......................... 3

Table 2. Summary of simulations and material models ......................................................................... 9 
INTENTIONALLY BLANK 


\section{ACKNOWLEDGMENT}

The authors would like to thank Jason Hales, Giovanni Pastore, Ben Spencer, and Rich Williamson (Idaho National Laboratory) for their collaboration and interaction on the development and use of BISON for this work, as well as the MOOSE code developers for their technical support for this work. The high-performance computing facilities (FALCON) made available by Idaho National Laboratory, as well as the Newton computing cluster at the University of Tennessee, are gratefully acknowledged. Research is sponsored by the Advanced Fuels Campaign of the Fuel Cycle R\&D program, Office of Nuclear Energy, US Department of Energy, under contract DE-AC05-00OR22725 with UT-Battelle, LLC. 
INTENTIONALLY BLANK 


\begin{abstract}
In order to improve the accident tolerance of light water reactor (LWR) fuel, alternative cladding materials have been proposed to replace zirconium (Zr)-based alloys. Of these materials, there is a particular focus on iron-chromium-aluminum (FeCrAl) alloys due to much slower oxidation kinetics in high-temperature steam than Zr-alloys. This should decrease the energy release due to oxidation and allow the cladding to remain integral longer in the presence of high temperature steam, making accident mitigation more likely. As a continuation of the development for these alloys, suitability for normal operation must also be demonstrated. This research is focused on modeling the integral thermomechanical performance of FeCrAl cladded fuel during normal reactor operation. Preliminary analysis has been performed to assess FeCrAl alloys (namely Alkrothal 720 and APMT) as a suitable fuel cladding replacement for Zr-alloys, using the MOOSE-based, finite-element fuel performance code BISON and the best available thermal-mechanical and irradiation-induced constitutive properties. These simulations identify the effects of the mechanical-stress and irradiation response of $\mathrm{FeCrAl}$ and provide a comparison with Zr-alloys. In comparing these clad materials, fuel rods have been simulated for normal reactor operation and simple steady-state operation. Normal reactor operating conditions target the cladding performance over the rod lifetime ( $\sim 4$ cycles) for the highest-power rod in the highest-power fuel assembly under reactor power maneuvering. The power histories and axial temperature profiles input into BISON were generated from a neutronics study on full-core reactivity equivalence for FeCrAl using the 3D full core simulator NESTLE. Evolution of the FeCrAl cladding behavior over time is evaluated by using steady-state operating conditions such as a simple axial power profile, a constant cladding surface temperature, and a constant fuel power history. The fuel rod designs and operating conditions used are based off the Peach Bottom BWR and design consideration was given to minimize the neutronic penalty of the FeCrAl cladding by changing fuel enrichment and cladding thickness. As this study progressed, systematic parametric analysis of the fuel and cladding creep responses were also performed.
\end{abstract}


INTENTIONALLY BLANK 


\section{INTRODUCTION}

In the wake of events at the Fukushima Daiichi Nuclear Power Plant, interest has been revived in pursuing ironchrome-aluminum alloys as alternative nuclear fuel claddings to traditionally used zirconium-based alloys. This focus is largely driven by the search for better cladding performance during transient reactor operation where the fuel cladding is exposed to a high temperature steam environment.

During a severe accident scenario, such as a loss-of-coolant-accident, a nuclear reactor may lose its capacity to cool its fuel. The fuel rod temperatures begin to increases, quickly reaching temperatures where the coolant begins to evaporate. This lowers the coolant level in the core and eventually uncovers the fuel. Without sufficient heat transfer from the fuel rods to the coolant, the temperature of the fuel and cladding will increase dramatically. In the case of traditional zirconium-based alloys, as the temperature of the cladding reaches $\sim 1200^{\circ} \mathrm{C}$ the zirconium rapidly begins to oxidize with $\mathrm{H}_{2} \mathrm{O}$ in the coolant and steam. This oxidation reaction causes both thinning of the Zr-alloy cladding as the metal reacts and releases large amounts of $\mathrm{H}_{2}$ gas into the reactor pressure vessel (Hofmann, 1998). With prolonged exposure the cladding can weaken and subsequently rupture, releasing fission products into the coolant.

In order to increase the safety margin of LWR fuel in severe accident scenarios, several alternative cladding materials have been proposed to replace the currently used zirconium-based alloys. Of these materials, there is a particular focus on select iron-chrome-aluminum ( $\mathrm{FeCrAl})$ alloys because they present slower oxidation kinetics in high-temperature steam than zirconium-based alloys (K. A. Terrani, Zinkle, S. J., Snead, L. L., 2014). This increased oxidation resistance may give more time to mitigate any further damage resulting from an accident.

By changing the cladding material, however, the neutronic characteristics of the core will change. FeCrAl alloys show a thermal neutron cross-section nearly $\sim 12-16 \times$ greater than Zr-alloys. This decreases the reactivity of the core, subsequently decreasing the potential cycle length for operation (K. A. Terrani, Zinkle, S. J., Snead, L. L., 2014) . To counteract this, fissile material may be added in the form of increased enrichment or increased fuel mass. Alternatively, the cladding thickness might be decreased, effectively reducing the neutronic penalty from using the alloy. In this study, all three changes are considered.

Information is needed to determine the suitability of iron-chrome-aluminum alloys as fuel cladding and assess safety margins for their operation. Because these alloys differ widely from zirconium in a variety of material properties, their effect on reactor operation should also be assessed. Failure mechanisms and behavioral models unique to the use of FeCrAl cladding are key for developing predictive fuel performance capabilities.

This report fulfills fiscal year 2016 (FY16) milestone number M3FT-16OR020205033 within Work Package FY16-16OR020205031 at ORNL for the DOE-NE Advanced Fuels Campaign. 


\section{MODELING APPROACH}

In order to compare the predicted in-reactor performance of FeCrAl cladding with Zircaloy and assess effects from irradiation creep, thermal creep, and swelling, several geometric and material models were implemented in to the BISON fuel performance code. BISON is a finite-element simulation tool for nuclear fuel elements that is based on the Multiphysics Object Oriented Simulation Environment (MOOSE) framework (Williamson et al., 2012). It utilizes a Jacobian-Free Newton-Krylov method to solve coupled systems of non-linear partial differential equations while leveraging the scalability of parallel computing. Because of the expandability of the MOOSE framework (Gaston, Newman, Hansen, \& Lebrun-Grandie, 2009), BISON can incorporate a host of materials as well as behavioral models for integral fuel performance modeling. It has the capability to model complex thermo-mechanical behavior from both discrete and smeared pellet fuel meshes, fuel-cladding gap and plenum, and the evolution of various fuel and cladding materials over their operation.

Two separate analyses were performed using BISON for this study. The first analysis is a comparison of FeCrAl with Zircaloy-4 fuel cladding over three different conditions of reactor operation. This analysis compares the zircaloy cladding, using the previously developed cladding models in BISON, with recently implemented FeCrAl cladding models. These new models are also used to examine the effects of creep and swelling on the in-reactor performance of the fuel cladding.

The second analysis is motivated by results from the first and consists of individual examination of the FeCrAl cladding and $\mathrm{UO}_{2}$ fuel creep models. For this analysis, separate evaluations are performed for each the cladding and the fuel. FeCrAl thermal and irradiation creep properties are examined to provide performance bounds for developmental alloys, where little data is available. Fuel creep is evaluated because of uncertainty in modeling compliance of the fuel without modeling fracture using the fuel performance code. This evaluation aims to identify a range of expected fuel behavior by examining the irradiation and thermal creep rate currently implemented in BISON and described in MATPRO (Hagrman, Allison, \& Berna, 1995). Without sufficient stress

relief mechanisms, such as cracking, the calculated fuel creep might be greatly over predicted; this can influence the mechanical interaction between the fuel and cladding and ultimately over predict calculated cladding stresses.

This study expands upon a previous core equivalence study (George, Powers, Maldonado, Worrall, \& Terrani, 2015) targeting the cycle length effects of using iron-chrome-aluminum alloys as alternative fuel cladding for the Peach Bottom BWR by incorporating aspects of integral fuel performance. Data from this previous study was used in order to create representative reactor operation data for the fuel simulations in BISON.

\subsection{GEOMETRIC MODELS}

Geometric models for this study are based on available data for the Peach Bottom BWR (Larsen, 1978). Where data is unavailable, representative values have been assumed. Two-dimensional, axisymmetric fuel rod geometries (shown in Table 1) were created for both Zircaloy and FeCrAl. The cladding thickness, fuel radius, and fuel enrichment for the FeCrAl cladded rod was chosen based on the impact of the neutronic penalty over the reactor cycle, while maintaining the same cladding outer radius. For this study, the FeCrAl cladding is half the thickness of the Zircaloy cladding. This results in $~ 14 \%$ more fuel mass. Additional fuel enrichment was also added to further improve the fuel reactivity. 
Table 1. Fuel geometry specifications for $2 \mathrm{D}$ axisymmetric fuel performance analyses

\begin{tabular}{llllll}
\hline Cladding Material Fuel Radius $(\mu \mathrm{m})$ & Gap Thickness $(\mu \mathrm{m})$ & Cladding Thickness $(\mu \mathrm{m})$ & Fuel Length $(\mathrm{m})$ & Cladding Length $(\mathrm{m})$ & Enrichment $(\%$ U-235) \\
\hline Zircaloy & 4400 & 100 & 600 & \multirow{2}{*}{3.66} & 4.08 \\
FeCrAl & 4700 & 100 & 300 & & 4.11 \\
\hline
\end{tabular}

- This produces a total outer radius of $5100 \mu \mathrm{m}(.51 \mathrm{~cm})$ for both cladding types.

These models are simplified by using smeared pellet fuel meshes (mesh example shown in Figure 1). Meshes are generated using second-order elements. In the figure, elements in the $\mathrm{UO}_{2}$ fuel region are shown in green, and elements in the cladding region are shown on the right, in grey.

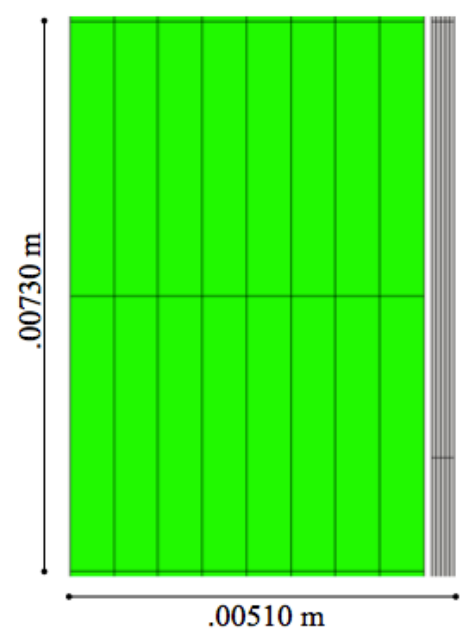

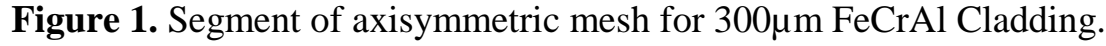

\subsection{CONSTITUTIVE AND BEHAVIORAL MODELS}

While BISON already contains many established material models for fuel performance, models for FeCrAl cladding had to developed and implemented. Constitutive models are already established for $\mathrm{UO}_{2}$ fuel, gap/plenum behavior, and Zircaloy cladding. However, it is important to note that fuel creep models remain a challenge within BISON, and for the majority of the analysis described in this report, fuel creep was not included. The effect of this assumption will be analyzed separately in a later section.

To simulate the $\mathrm{UO}_{2}$ fuel, material properties are determined using previously developed models including; NFIR data on thermal properties (based on temperature and burnup dependence); temperature dependent mechanical properties; fuel swelling, densification, and relocation; and fission gas release [( al., 2014)].

The gap and plenum regions of the fuel are modeled by using a previously developed gap conductance model, fission gas release, and plenum pressure model (Williamson et al., 2012). The plenum pressure is determined based on the amount of initial plenum fill-gas as well as fission gas released into plenum and the overall plenum volume. Mechanical interactions between the fuel and cladding surfaces in these simulations follow a penalty formulation to prevent surfaces from overlapping and the contact surfaces are frictionless (Hales et al., 2014). 
This simplification implies that there will be no axial elongation in the cladding due to fuel ratcheting or additional elongation as the fuel expands during mechanical contact (Hales et al., 2014; Olander, 1976).

Models used for the Zircaloy-4 cladding include thermal and mechanical properties based on temperature, neutron fluence, initial oxygen concentration, and cold-working factor; thermal and irradiation creep; and irradiation growth. These are standard models in BISON.

Material models for FeCrAl were made using datasheets for two FeCrAl alloys: Kanthal Alkrothal 720 ("Kanthal Alkrothal 720 Datasheet,") and Kanthal APMT. ("Kanthal APMT Datasheet,") Material properties from the datasheets were fit to curves based on their dependencies and implemented into BISON. These models are based on available thermo-physical, mechanical, and irradiation properties and include: thermal conductivity, specific heat, elastic modulus, Poisson's ratio, density, thermal creep, and irradiation swelling.

\subsection{IMPLEMENTATION AND COMPARISON OF CREEP, GROWTH, AND SWELLING MODELS}

Several key models implemented for FeCrAl cladding include irradiation creep, thermal creep, and irradiation swelling. These are compared with corresponding Zircaloy models, to identify expected cladding deformation behavior under various stress, temperature, and neutron flux conditions.

The deformation in the FeCrAl cladding over time in BISON, as shown in equation 1, is calculated as the sum of the elastic, thermal, swelling, and creep strains rates. Where Hooke's law describes the elastic strain $\left(\dot{\varepsilon}_{e}\right)$, a thermal expansion relation defines strain induced by a change in temperature $\left(\varepsilon_{t h}\right)$, and the swelling $\left(\dot{\varepsilon}_{s}\right)$ and creep $\left(\dot{\varepsilon}_{c}\right)$ relations are described later in this section. This process is similar for Zircaloy cladding, however, instead of isotropic irradiation swelling, Zircaloy exhibits anisotropic irradiation growth.

$$
\dot{\varepsilon}_{\text {Total }}=\dot{\varepsilon}_{e}+\dot{\varepsilon_{t h}}+\dot{\varepsilon}_{S}+\dot{\varepsilon}_{c}
$$

Irradiation swelling and irradiation creep models (shown in equations 2 and 3, respectively) for FeCrAl were developed to reflect estimates of the material response for ferretic alloys (Garner, Toloczko, \& Sencer, 2000). Note that there is no irradiation creep contribution from swelling-enhanced creep; this is intentionally unused because of the low cumulative dose expected in the cladding relative to the incubation dose for the onset of void swelling. The irradiation-swelling model used for $\mathrm{FeCrAl}$ is expressed as a linear function scaling with dose:

$$
\dot{\varepsilon_{S}}=A \cdot \varphi
$$

Where $\dot{\varepsilon}_{S}$ is the volumetric strain rate due to swelling, $A$ is a volumetric swelling constant $\left(.05 \%-\mathrm{dpa}^{-1}\right)$ and $\varphi$ is the irradiation damage in the cladding in displacements-per-atom (dpa). The damage rate in these models is adapted from expected displacement damage at the midplane of a BWR core over an effective-full-power-year (Heinisch, Greenwood, Weber, \& Williford, 2004) and converted to the fast neutron flux. This conversion is performed because BISON does not natively calculate the neutron energy spectrum from fission, and therefore cannot calculate the displacement damage.

The creep strain $\left(\dot{\varepsilon}_{c}\right)$ can further be divided into two distinct contributions for thermal $\left(\dot{\varepsilon}_{c, t h}\right)$ and irradiation $\left(\dot{\varepsilon}_{c, i r r}\right)$ creep. The irradiation creep model implemented is described in equation 3 , as:

$$
\dot{\varepsilon}_{c, i r r}=B \cdot \varphi^{m} \cdot \sigma^{n}
$$

Where, $B$ is the irradiation creep prefactor $\left(5 \times 10^{-5} \mathrm{MPa}^{-1}-\mathrm{dpa}^{-1}\right), \varphi$ is the displacement damage in the cladding (dpa), and $\sigma$ is the effective stress (MPa). In this equation, the exponents of both displacement damage, $m$, and 
flux, $n$, are considered to be 1 .

The steady-state thermal creep model for the FeCrAl alloy, a power-law creep equation to describe dislocation creep (shown in Equation 4), is adapted from Fecralloy (Saunders, Evans, Li, Gohil, \& Osgerby, 1997). The strain rate for this model is expressed as:

$$
\dot{\varepsilon}_{c, t h}=C \cdot \sigma^{n} \cdot \exp \left(-\frac{Q}{R T}\right)
$$

Where, $C$ is the creep pre-exponential $\left(5.96 \times 10^{-24}\right), \sigma$ is the effective stress in Pa, $n$ is the stress fitting parameter (5.5), $Q$ is the creep activation energy $\left(\sim 3.92 \times 10^{5} \mathrm{~J}_{-} \mathrm{mol}^{-1}\right), T$ is the temperature in $\mathrm{K}$, and $R$ is the gas constant $\left(\mathrm{J}-\mathrm{mol}^{-1}-\mathrm{K}^{-1}\right)$. The creep pre-exponential, $C$, was modified to $5.96 \times 10^{-24}$ from its original value of $5.96 \times 10^{-27}$ in order to match experimental results more accurately (K. A. Terrani, Karlsen, T.M., Yamamoto, Y., 2015).

For Zircaloy, steady-state irradiation and thermal creep rates (shown in equations 5, 6) are from (Limbäck \& Andersson, 1996). The irradiation creep rate expression is implemented analogously to the expression for $\mathrm{FeCrAl}$, however, with different constants.

$$
\dot{\varepsilon}_{c, i r r}=D \cdot \varphi^{m} \cdot \sigma^{n}
$$

Here, the irradiation creep constant is $\mathrm{D}\left(\sim 9.88 \times 10^{-28}\right)$, and the irradiation creep strain rate is a function of $\varphi$, the fast neutron flux $\left(\#-\mathrm{m}^{-2}-\mathrm{s}^{-1}\right)$, and $\sigma$, the effective stress (MPa). The flux exponent, $(m)$, is .85 , and the stress exponent, $(n)$, is 1 .

The thermal creep rate is expressed using the Matsuo model, with constants determined for Zircaloy-4. Thermal creep includes an irradiation hardening contribution, which acts to slow the creep rate (shown in equation 7).

$$
\begin{gathered}
\dot{\varepsilon}_{c, t h}=3 e 5 \cdot\left(\frac{E}{T}\right) \cdot\left(\sinh \frac{a_{i} \cdot \sigma}{E}\right)^{2} \cdot \exp \left(-\frac{201,000}{R T}\right) \\
a_{i}=650 \cdot\left(1-0.56 \cdot\left(1-\exp \left(-8.8334 \mathrm{e}^{-} 33 \cdot \Phi^{1.3}\right)\right)\right)
\end{gathered}
$$

The irradiation growth model used (equation 8) is the Franklin Model (Franklin, 1982), implemented as described by (Rashid, Dunham, \& Montgomery, 2004):

$$
\frac{\Delta L}{L}=8.68 e^{-25} \cdot(\varphi t)^{.845}
$$

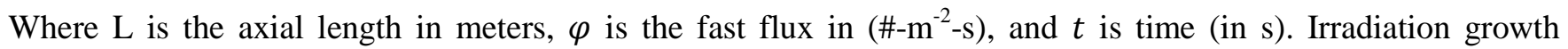
conserves the overall volume of the material; cladding elongates along the growth direction and reduces size in the other directions. Therefore, a corresponding strain acting to reduce the cladding radius and thickness will develop.

Plots showing a simple comparison between thermal and irradiation creep for FeCrAl and Zircaloy for three stresses are shown in Figure 2. For this comparison, the elastic modulus of Zircaloy is assumed to be 75 GPa and there is no contribution from irradiation hardening in the thermal creep rate. 

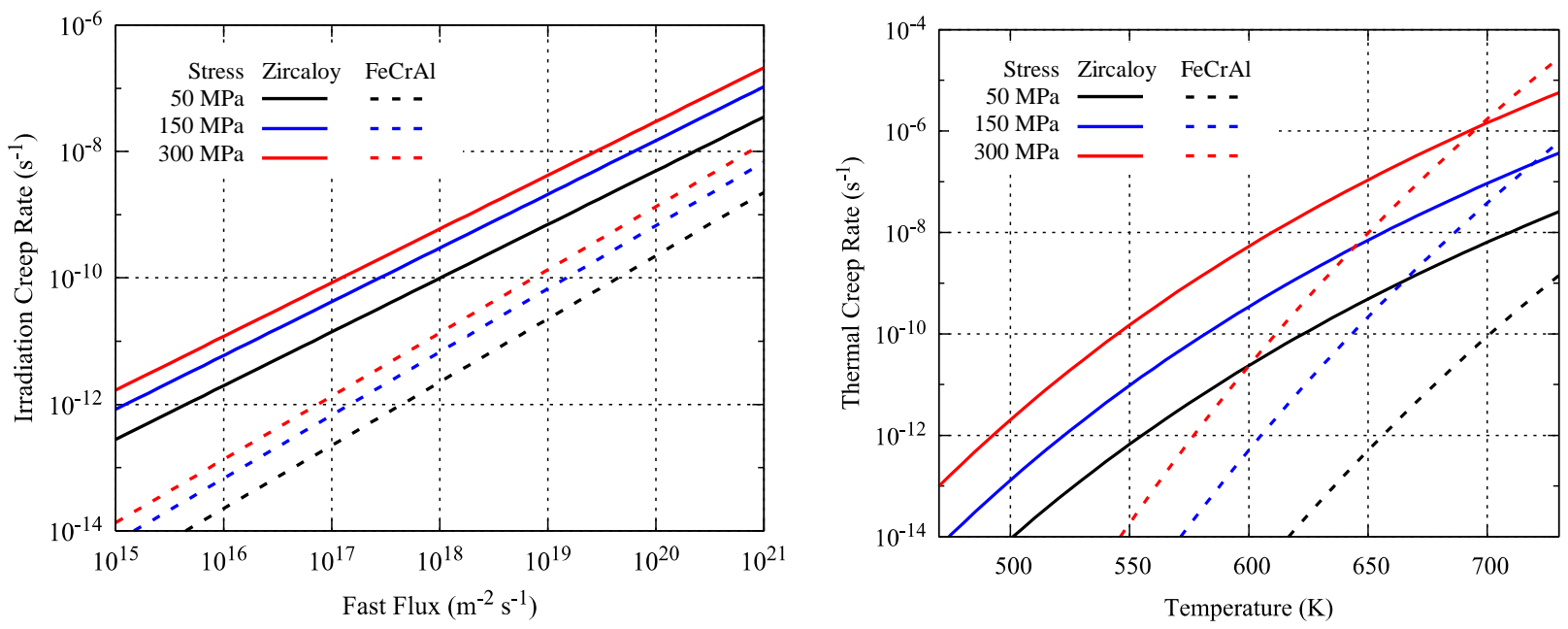

Figure 2. Irradiation (left) and thermal (right) creep rate comparison for Zircaloy and FeCrAl.

These plots show the large difference in the creep behavior of the two cladding materials over a variety of anticipated reactor operating conditions and at varying stresses. This shows that the FeCrAl cladding will have much less creep deformation, and in the absence of instantaneous plasticity, should experience less stress-relief from deformation during fuel-cladding mechanical contact than the Zircaloy-4 cladding. 


\subsection{BOUNDARY CONDITIONS AND SIMULATION INPUT PARAMETERS}

Data from the neutronics analysis was provided to BISON as boundary conditions. These include axial power profiles of the fuel and temperature profiles of the cladding outer surface. This power and temperature data generated was for the highest power fuel rod in the highest power fuel assembly at each depletion step in the calculation, effectively the most limiting rod in the core, and was modeled in effective full power seconds of the reactor. This data is organized as a fuel rod average power history and a series of axial power profiles. Figure 3 shows the rod average power history for both the FeCrAl and Zircaloy cladded fuel rods and a set of selected axial power profiles from the FeCrAl-cladded fuel. These axial power profiles, shown on the right in Figure 3 have been averaged and show the wide variation in power along the axial length of the fuel rod over time.

In order to target the average fuel rod behavior using this operational data, a separate set of fuel rods was run using an $80 \%$ power version of these histories. The dashed lines in Figure 3 show the reduced power histories for these fuel rods.

It is important to note that this operational data does not simulate reactor shutdown between cycles, which may cause increased wear on the fuel rod from repeated power ramping. These power histories cover three 18-month cycles and extend into a $4^{\text {th }}$ cycle ( 2100 days for FeCrAl, 1770 days for Zry). Because this data is generated for equilibrium cycle cores and targets the most limiting fuel rod in the core, the burnup of the fuel rods for both cladding materials is different.
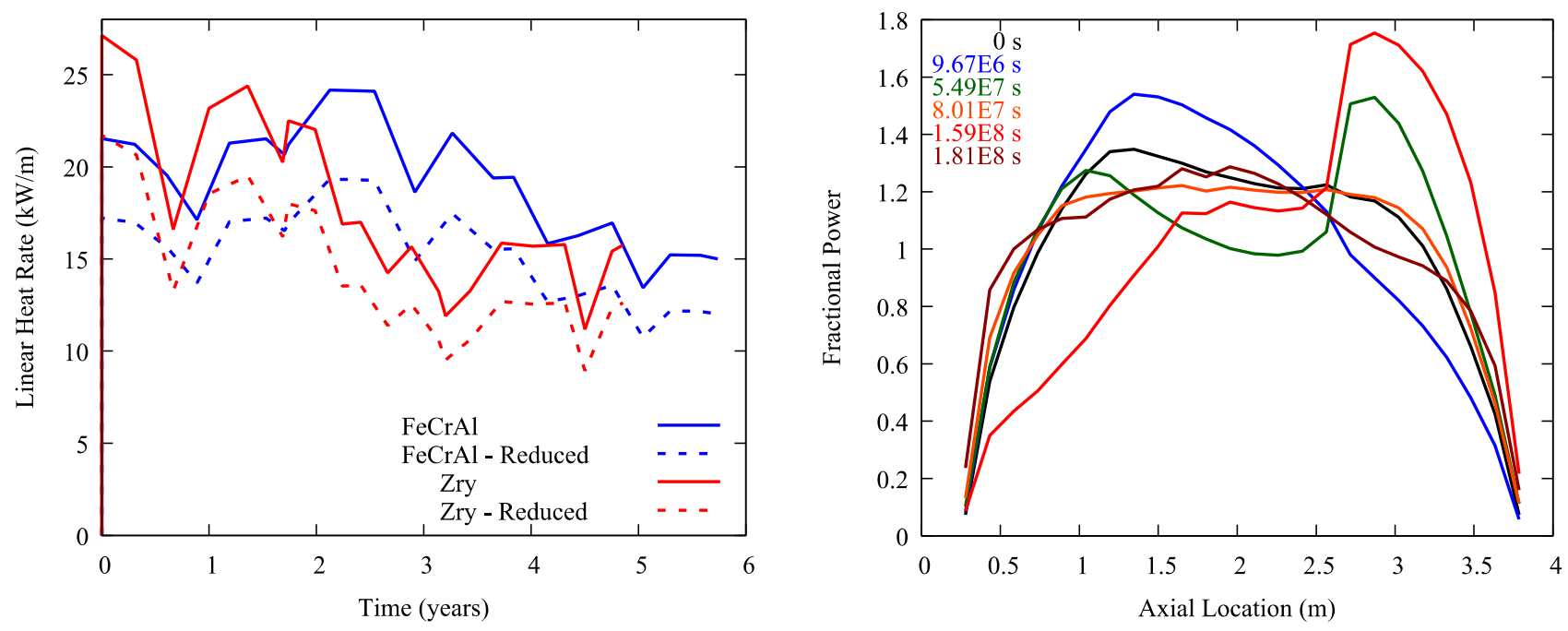

Figure 3. Power History and Selected Axial power profiles for Limiting and Average rod operation.

Simplified simulation data was constructed from the average rod power in order to more easily disseminate changes in the fuel rod over operation. In order to perform this analysis, a simplified power history and axial profile are used. This power history and axial power profile are shown in Figure 4 and consists of a relatively quick ( 12 hours) ramp to power with a simple axial power shape. After the initial power ramp, fuel rod power is then held constant at $\sim 18 \mathrm{~kW} / \mathrm{m}$ (this represents the average power).

Boundary conditions were used to apply provided coolant temperature profiles to the outside of the cladding along with the coolant pressure, and to apply the plenum pressure to the inside surface of the cladding and the outside of the fuel. The reactor operating pressure (7.136 MPa) was taken from the design document and also applied as a boundary condition to the outside of the cladding. The initial plenum pressure for the fuel rod is 5 
ATM ( .5 MPa), derived from a GE-9 fuel assembly, as data was not available for GE-12 or GE-14 fuel assemblies (Moore \& Notz, 1989).
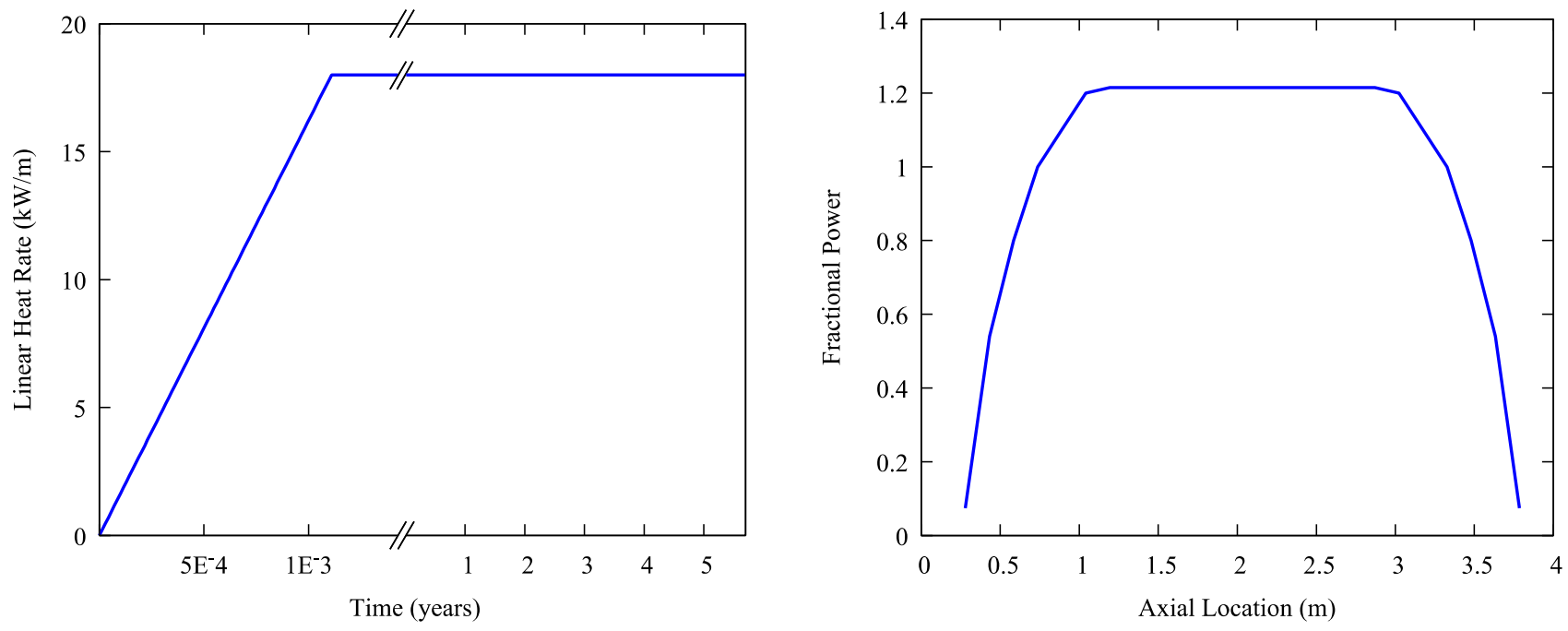

Figure 4. Power history and axial power profile for constant-power rod operation. 


\section{RESULTS AND DISCUSSION}

In total, five different simulations were performed for three different modes of operation. As shown in Table 2, there are four simulations for FeCrAl cladding corresponding to the inclusion of different material models, and a single simulation for Zircaloy using established material models implemented in BISON. This was done to distinguish integral effects from individual properties of the FeCrAl cladded fuel rods during reactor operation and compare these against Zircaloy cladding.

Table 2. Summary of simulations and material models

\begin{tabular}{|c|c|c|c|c|c|}
\hline $\begin{array}{l}\text { Cladding } \\
\text { Material }\end{array}$ & $\begin{array}{l}\text { Elastic } \\
\text { Properties }\end{array}$ & $\begin{array}{l}\text { Thermal } \\
\text { Creep }\end{array}$ & $\begin{array}{l}\text { Irradiation } \\
\text { Swelling } \\
\end{array}$ & $\begin{array}{l}\text { Irradiation } \\
\text { Creep }\end{array}$ & $\begin{array}{l}\text { Irradiation } \\
\text { Growth }\end{array}$ \\
\hline FeCrAl & $\mathbf{X}$ & $\mathbf{X}$ & $\mathbf{X}$ & $\mathrm{X}$ & \\
\hline $\mathrm{FeCrAl}$ & $\mathbf{X}$ & $\mathbf{X}$ & $\mathbf{X}$ & & \\
\hline $\mathrm{FeCrAl}$ & $\mathbf{X}$ & $\mathbf{X}$ & & & \\
\hline FeCrAl & $\mathbf{X}$ & & & & \\
\hline Zircaloy & $\mathbf{X}$ & $X$ & & $X$ & $X$ \\
\hline
\end{tabular}

From these simulations, several parameters were utilized to determine the state of the fuel and cladding. These metrics were chosen to reflect current fuel safety criteria and include ( $\underline{\mathrm{OECD}})$ : peak and average fuel centerline temperatures, cladding axial elongation, maximum cladding radial displacement, fission gas production and release, plenum pressure and volume, and maximum cladding hoop stress.

\subsection{LIMITING-POWER OPERATION}

Peak and average fuel centerline temperatures for the most limiting case are shown on left and right of Figure 5, respectively. The plot on the left compares the peak fuel centerline temperatures for the various simulations of FeCrAl and Zircaloy-cladded fuel rods. The plot on the right compares the peak and average fuel centerline temperatures of the full FeCrAl-cladded simulation and the Zircaloy-cladded fuel rod.

As shown on the left, there is a very small change in fuel centerline temperature among the FeCrAl family of curves over the simulated reactor operation. There is a slight $(\sim 40 \mathrm{~K})$ change over 1-3 years where isotropic swelling in the cladding, expands the cladding diameter and increases the thickness of the fuel-cladding gap by a small amount. Increasing the gap thickness impedes heat transfer from the fuel and therefore raises the fuel temperature. As the fuel swells, it eventually closes this gap, improving the gap conductance, consequently, lowering the fuel temperature.

There is a slight change in the fuel temperature $(\sim 20 \mathrm{~K})$ in the elastic model starting around 4 years. This arises because the cladding in this particular simulation only allows elastic deformation, and therefore restricts the fuel from expanding more than the other models. Aside from this, the fuel centerline temperatures of the FeCrAlcladded, fuel rods overlap for much of the simulation. This indicates that the difference in FeCrAl material models has a limited effect on the fuel centerline temperatures.

As previously mentioned, the large difference in fuel temperature profiles between the Zircaloy and FeCrAl cladded fuel rods is due to the differing power histories and axial profiles that resulted from optimization of the full-core neutronics simulations for each cladding material. 
The difference between the peak and the average fuel centerline temperatures (shown on the right in Figure 5) occurs due to variations in the axial power profiles. It is important to note that the FeCrAl simulations maintain a consistently greater average temperature than the Zircaloy rods after 16 months. Increasing the fuel temperature greatly influences thermally assisted phenomena, such as fission gas release, and is mentioned later.
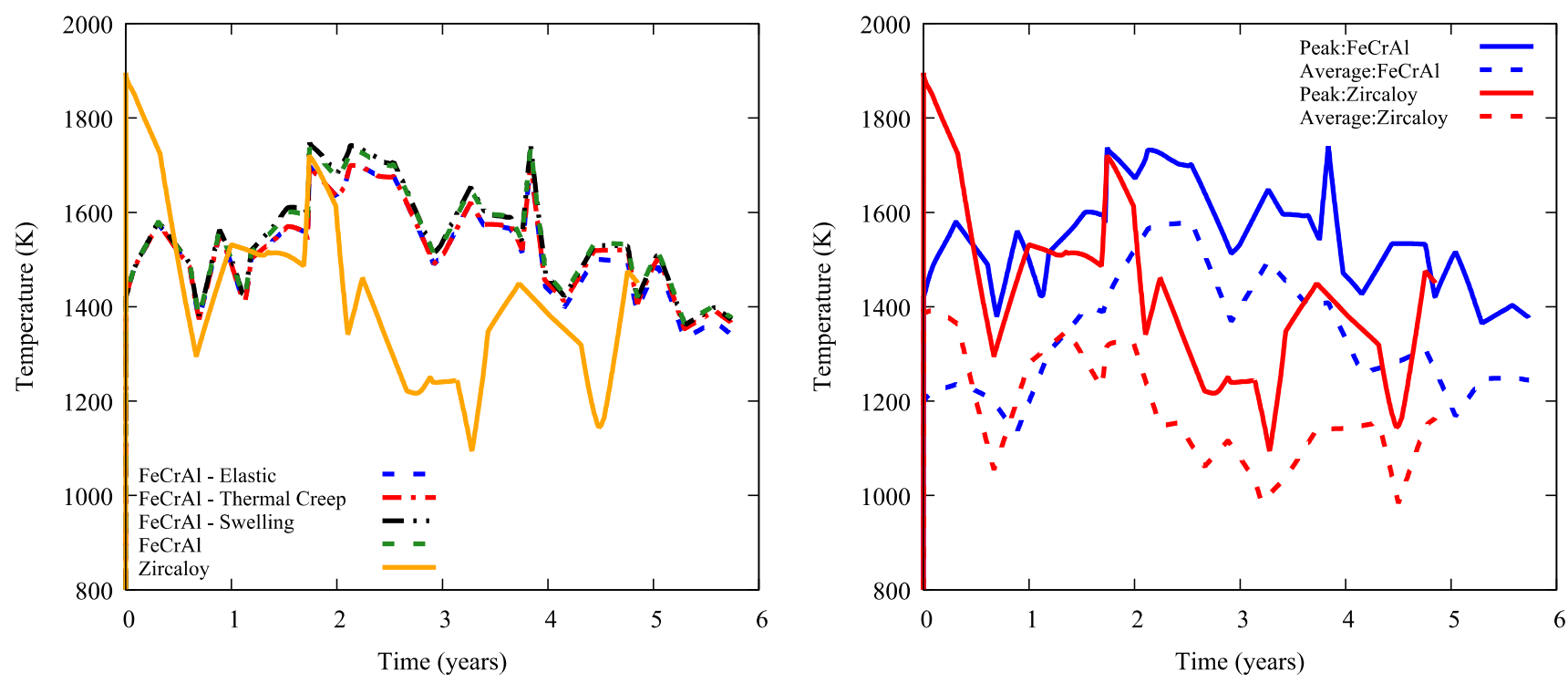

Figure 5. Peak and average fuel centerline temperatures during the simulation.

The axial elongation and maximum radial displacements are shown on the left and right in Figure 6, respectively. The initial axial elongation in both $\mathrm{FeCrAl}$ and Zircaloy-cladded fuel rods is driven by the thermal expansion of the cladding during its rise to reactor coolant temperature, and subsequently, the fuel operating temperature. Immediately after the initial thermal expansion, there is a noticeable deviation between the FeCrAl curves based on the irradiation swelling of the cladding. In the cases without swelling, the cladding axial elongation is relatively constant until mechanical contact occurs. After mechanical contact has occurred, there is a reduction in length as the fuel expands the cladding radially due to Poisson's effect. This is similar for the fuel rods that include the irradiation-swelling model, however, the axial swelling appears to nearly offset the length reduction from radial expansion. The Zircaloy-cladded fuel rods show a similar axial elongation effect due to anisotropic irradiation growth, until mechanical contact occurs. There is a small effect from the additions of thermal and irradiation creep in the FeCrAl cladding. Creep deformation allows the cladding to relax stresses that form during the mechanical interaction with the fuel. This allows the cladding radius to increase, subsequently decreasing the axial elongation.

Similar to the axial elongation, the initial radial expansion in the FeCrAl and Zircaloy-cladded fuel rods is due to thermal expansion. The radial displacements, shown in Figure 6, are the maximum values across the length of the rod. While these values are only for the cladding tube wall itself, the ends of the tube near the end caps affect them. Because the end caps do not creep down as much as the wall, the displacements near the ends are represented until mechanical contact pushed them out. For the Zircaloy cladded fuel rod, irradiation growth also reduces the cladding radius at the end caps. This can be identified in the plot, as the displacement decreases after thermal expansion and before the fuel-cladding mechanical contact. A similar effect is discernable due to irradiation swelling of the FeCrAl cladding. As the cladding swells, the end caps of the fuel rod swell, increasing the radial displacement of the cladding, and even after mechanical contact occurs, the swelling of the cladding thickness is still evident. 
Gap closure and subsequent mechanical contact occurs in the Zircaloy after 301 days where in the FeCrAl it takes $\sim 760$ days. This is identified by the transition from compressive to tensile cladding hoop stress in Figure 7. After mechanical contact occurs in the FeCrAl-cladding, the radial displacement quickly begins to increase as the fuel swells. The simulation with simply elastic cladding properties only includes elastic deformation, so it constricts the fuel and undergoes no plastic deformation. Simulations including creep deformation allow the cladding to relieve stresses formed during mechanical contact by allowing radial expansion of the cladding.

For both cladding materials, the cladding elongation is less than $2 \mathrm{~cm}$ of the $4 \mathrm{~m}$ cladding tube ( $.5 \%)$ and the maximum radial displacement is nearly $70 \mu \mathrm{m}(\sim 1 \%)$. This shows that, while all of these rods satisfy the requirement of maintaining an equivalent strain below 2.5\% (in this case $\sim 1.5 \%$ ), the hoop strain for the FeCrAlcladded fuel rods is greater than the $1 \%$ limit at the end of life. This arises from the rigidity of the fuel, as fuel creep is neglected.
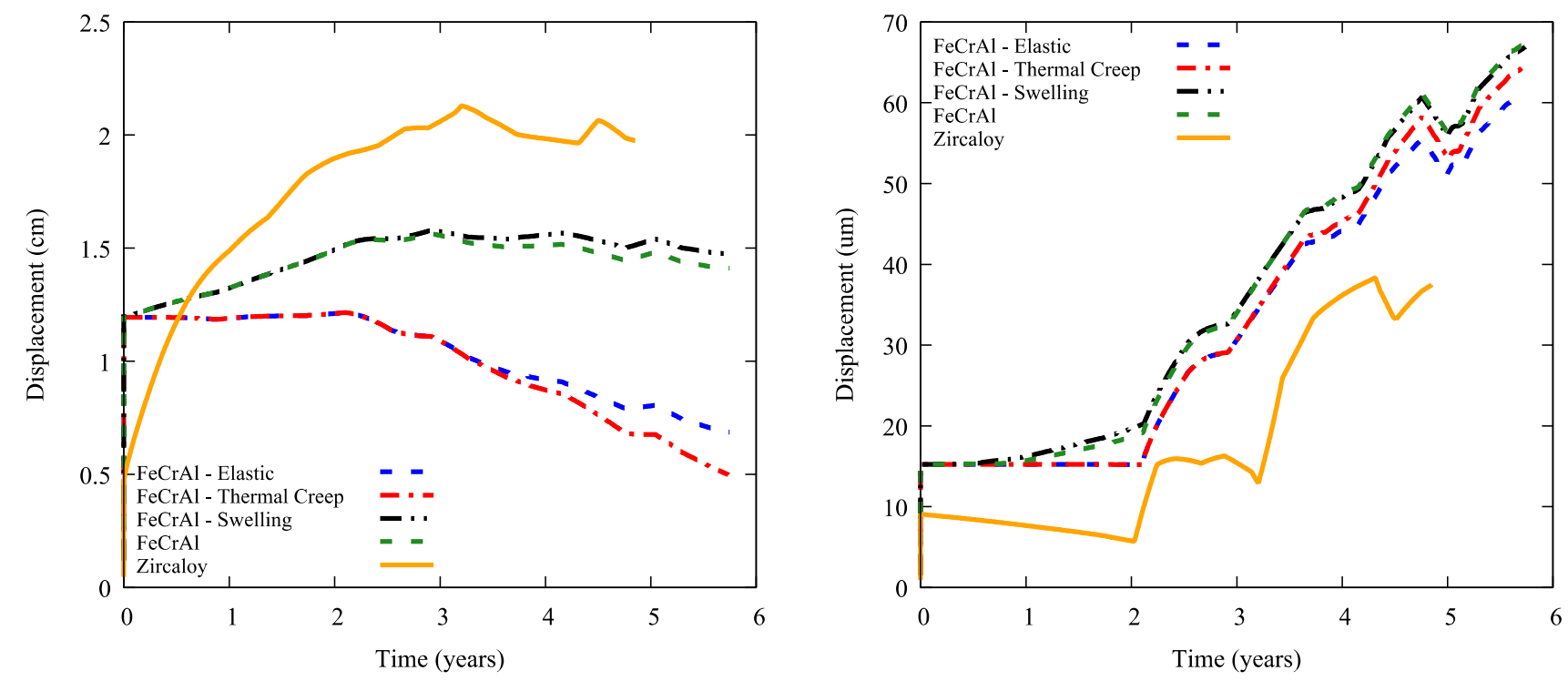

Figure 6. Axial elongation and maximum radial displacement of the cladding.

The maximum hoop stress in the cladding from each simulation is plotted over time and shown in Figure 7. The cladding is initially in a compressive stress state caused by the difference in the rod plenum pressure and the reactor coolant pressure. Because the FeCrAl cladding is half the thickness of the Zircaloy cladding, the hoop stresses that develop are nearly doubled in the FeCrAl cladding. The cladding essentially remains in this state, with minor contributions from increasing plenum pressure, differential irradiation growth or swelling, and a minor temperature gradient, until mechanical contact occurs. As the cladding is irradiated, irradiation swelling acts to expand the cladding. Azimuthal expansion of the cladding slightly prolongs the onset of gap closure, while radial expansion of the cladding reduces formation of hoop stresses.

Because the magnitude of thermal and irradiation creep for Zircaloy cladding is so large, the cladding tube begins to enclose around the fuel in order to relieve compressive stress from the pressure differential across it; this is know as 'cladding creep-down. The hoop stress in the Zircaloy reaches a maximum value of $160 \mathrm{MPa}$ after extended mechanical contact, and generally remains in this regime. As mentioned in Section 2.3, the creep strain rate of FeCrAl cladding is nearly 4 orders of magnitude lower than Zircaloy at relevant conditions. Thus, the FeCrAl cladding does not experience creep-down at nearly the same rate and fuel swelling dominates the gap closure. After mechanical contact occurs in the FeCrAl-cladded fuel rods, the hoop stresses rapidly begin to increase due to both a lack of compliance in the fuel and the cladding. 
A large reduction in the hoop stress ( $1000 \mathrm{MPa})$ develops due to the inclusion of the thermal creep model because of its sensitivity to high stresses (the stress exponent in equation 4 is 5.5), with modest effects from both the irradiation creep and swelling. Many of the fluctuations in the hoop stress histories are caused by temperature variations across the length of the fuel as the axial power profiles change. This develops local areas of increased fuel temperatures that can increase the fuel thermal expansion and swelling in those areas. Increased temperatures along the fuel cladding can also greatly increase stress relaxation in those areas by increasing the thermal creep rates, as they are also very sensitive to temperature.

While this shows stresses in the FeCrAl cladding can quickly reach the yield strength of the alloy, it also emphasizes that an overall fuel rod design change may be necessary and should be considered for alternative cladding materials.

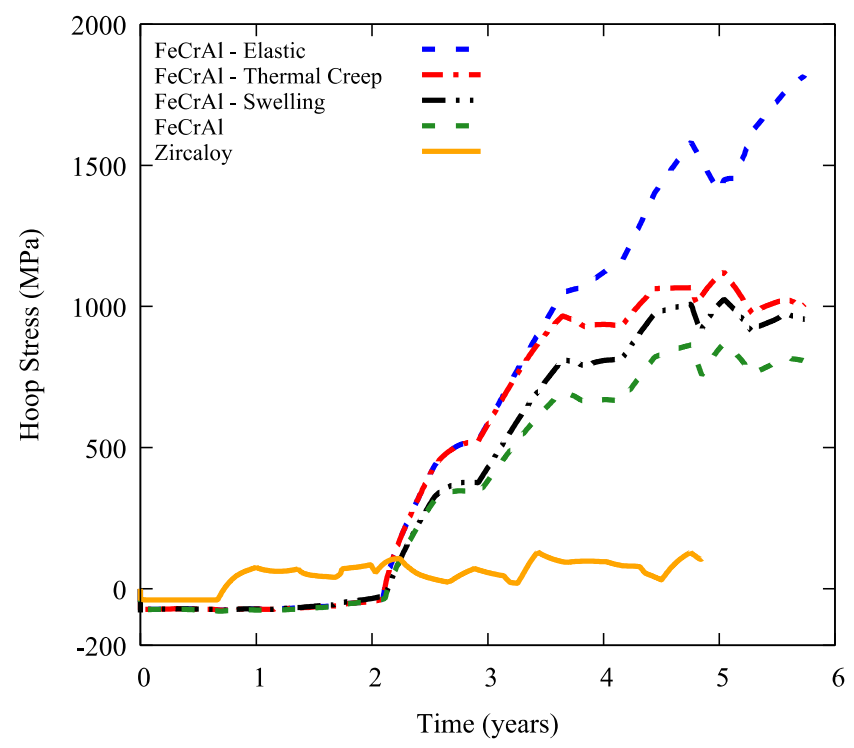

Figure 7. Maximum hoop stress in the cladding.

Fission gas production and release behavior for these fuel rods is shown in Figure 8.

Fission gas production (in mol- $\mathrm{m}^{-3}$ ) is shown on the left, and is consistent for the fuel rods based on the cladding material. The variation between the Zircaloy and FeCrAl cladded rods is due to the increased power production in the Zircaloy cladded rod towards the beginning of life and the FeCrAl-cladded rod much later. Because all fuel rods with the FeCrAl cladding follow the same power history, the fission gas generated is the same.

Fission gas release behavior, however, is much different across different rods. Fission gas released to the fuel rod plenum is shown on the right as a percentage of the fission gas produced. The fission gas release in the FeCrAl cladded fuel rods increases sharply beginning at 16 months, and is consistent with a sharp rise in the rod average temperature (Figure 5). A substantial effect from irradiation swelling can also be seen beginning at $\sim 2$ years and running throughout the fuel rod lifetime. This is presumably because of the radial expansion of the fuel cladding and the subsequently increased fuel temperature from a larger fuel-cladding gap. The fission gas released in the FeCrAl cladded rods increases to nearly $4 x$ the amount in the Zircaloy-cladded rods. Later in life, the percentage of gas released then begins to taper off as less gas is released relative to the amount produced.

Fission gas release in Zircaloy-cladded fuel rods is much different because the power history varies greatly with 
the $\mathrm{FeCrAl}$ cladded fuel rods. At the beginning of life, the fuel centerline temperature ramps to $1900^{\circ} \mathrm{K}$, and the rod immediately experiences significant fission gas release. From there the percentage of gas released decreases until the fuel experiences elevated temperatures again at $\sim 20$ months.

In this mode of operation it is difficult to perceive effects from fission gas on the overall performance of the fuel rod. Nonetheless, it can be used to help identify behavior of the plenum pressure in the fuel rod.
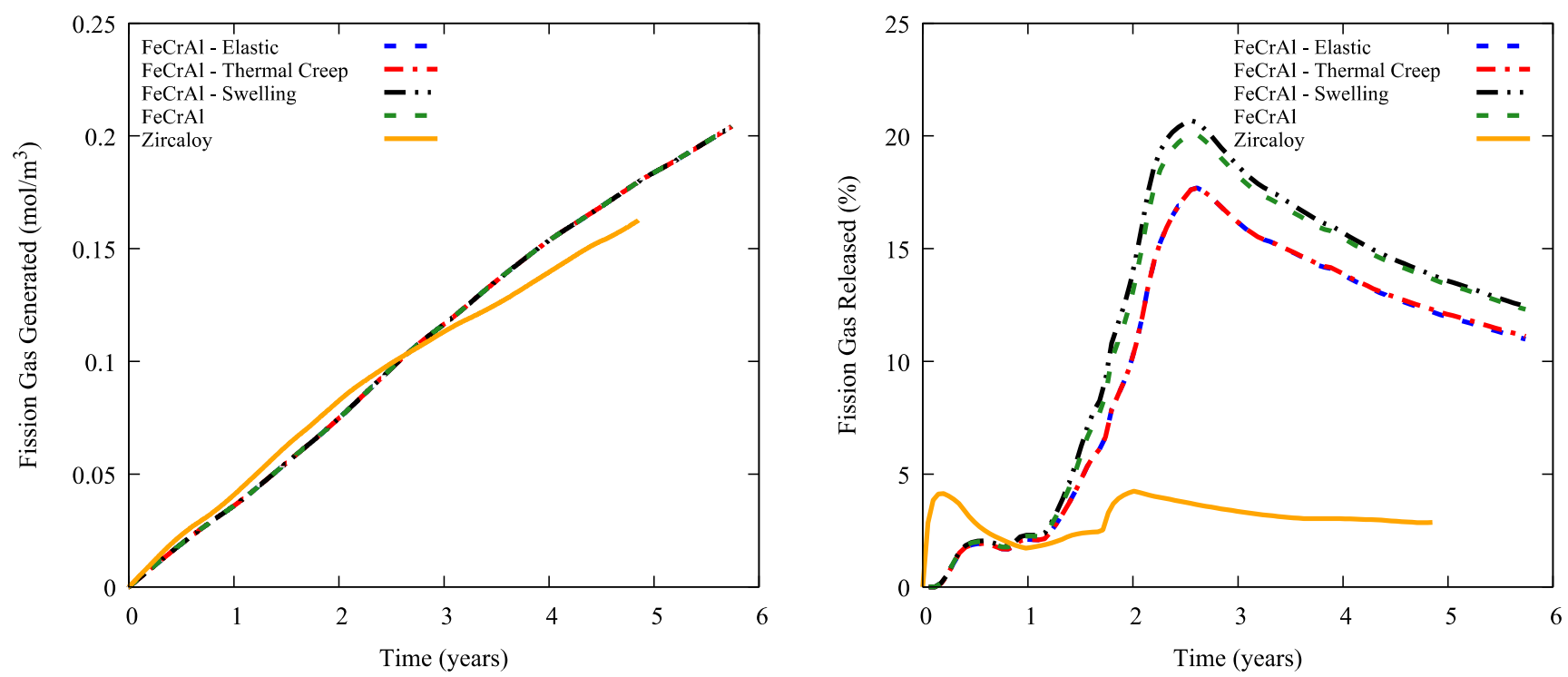

Figure 8. Fission gas generation in the fuel and release to the plenum.

The plenum pressure and volume are shown in Figure 9. As mentioned previously in Section 2.4, the initial rod fill-gas pressure is .5 $\mathrm{MPa}$ in the rod at standard temperature and pressure. This quickly increases as the fill gas is heated and the fuel and cladding thermally expand to their corresponding temperatures. At approximately 1 year, the FeCrAl cladded fuel rods begin significant fission gas release from the fuel into the plenum, greatly increasing the fuel rod plenum pressure. Because the Zircaloy cladded fuel rods experience much less fission gas release, the plenum pressure increase is greatly reduced. The scatter in these curves is largely due to the shifting temperature of the fuel and gap regions, where thermal expansion has a pronounced effect. The difference in the FeCrAl family of curves is due to irradiation swelling and the effect it has on fuel temperatures. The plenum pressure in the $\mathrm{FeCrAl}$ cladded rods remains below the reactor coolant pressure for the entire 3 cycles, indicating the cladding hoop stress generated from the pressure differential between the fuel rod and coolant pressure is compressive. This is important, as generation of a plenum pressure greater than the system coolant pressure can result in a condition of cladding outward expansion known as "cladding lift-off". In this condition the internal rod pressure acts to expand the cladding, thus, reopening the fuel-cladding gap, which can begin a thermal-feedback effect with the amount of fission gas released and the plenum pressure.

Plenum volume shows the effects of dimensional change of both the fuel and the cladding. The volume initially decreases as the fuel expands more than the cladding during the rise to operating temperature. The fuel then begins densification, leading to a small increase in the plenum volume. This is more evident in the FeCrAlcladded fuel rods as the there is a greater volume of fuel to densify and the cladding is less susceptible to creep deformation. The subsequent decrease in plenum volume is largely the axial and radial swelling of the fuel. There is a slight increase in the volume of some $\mathrm{FeCrAl}$ rods as irradiation swelling make a small contribution to cladding dimensions. 
Both the FeCrAl and the Zircaloy cladded fuel rods have a $100-\mu \mathrm{m}$ gap. With a greater gap radius due to greater fuel mass and decreases cladding thickness, the $\mathrm{FeCrAl}$ rods have a greater plenum volume in the room temperature state. This means that even after mechanical contact has closed the gap between the fuel and the cladding, the FeCrAl cladded rods will contain greater volume in the plenum regions of the fuel rod.
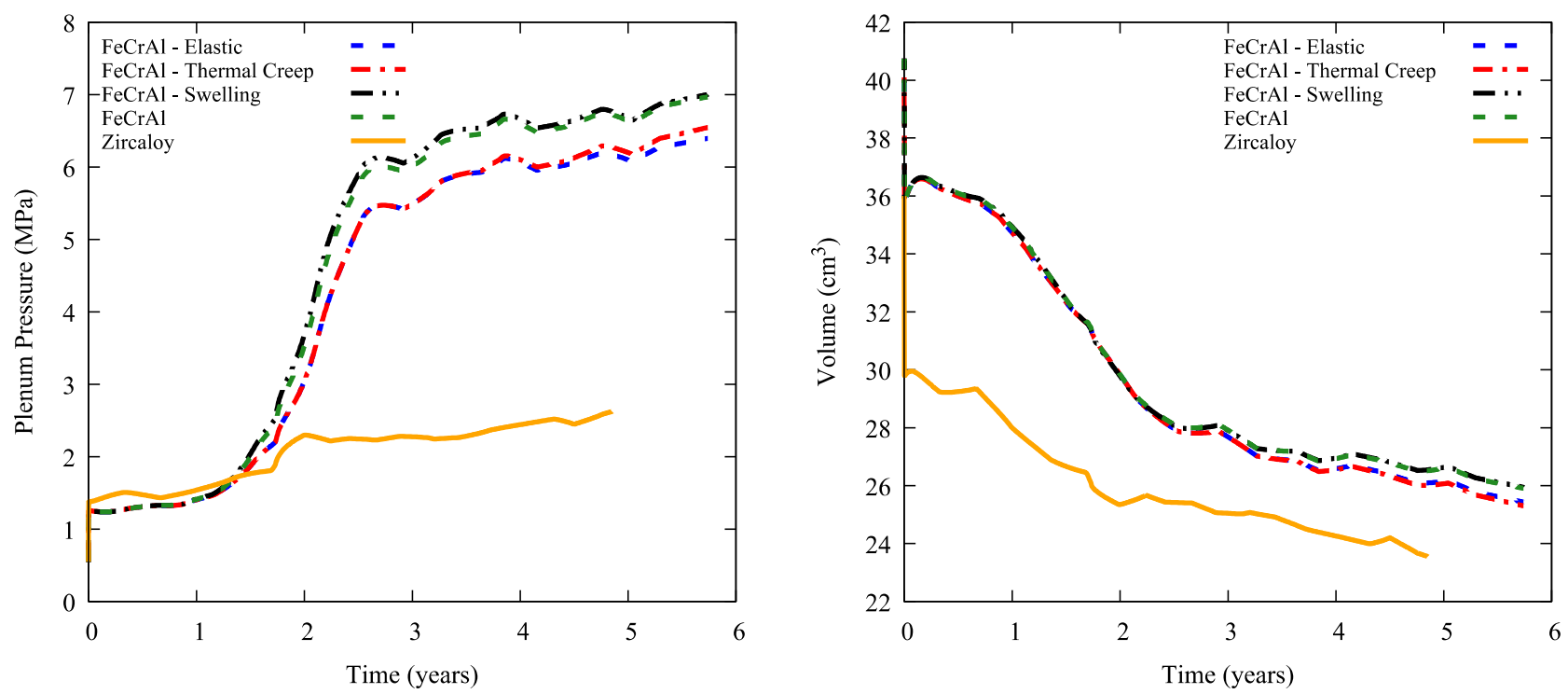

Figure 9. Fuel rod internal plenum pressure and gas volume. 


\subsection{AVERAGE-POWER OPERATION}

As described previously, the linear heat rates from the most limiting cases are scaled by $80 \%$ in order to more closely model the average fuel rod operation.

The peak and average fuel centerline temperatures are shown in Figure 10. Much like the results from the Limiting-Power Operation, there is very little difference in the maximum fuel centerline temperatures among the family of FeCrAl-cladded fuel rods. A small difference develops at $\sim 2$ years corresponding to a rapid release of fission gas into the rod plenum. This effect is larger in fuel rods that include irradiation swelling, where the fuel-cladding gap does not close until later in life.

As previously described, the difference between the Zircaloy and FeCrAl family of curves is due to the differing power history and axial power profiles generated from the neutronics analysis. The average temperatures between the cladding types are also much different. As shown in the plot on the right, the FeCrAl cladded fuel rods maintain a much greater average fuel centerline for much of the operation, beginning at about $\sim 2$ years. 

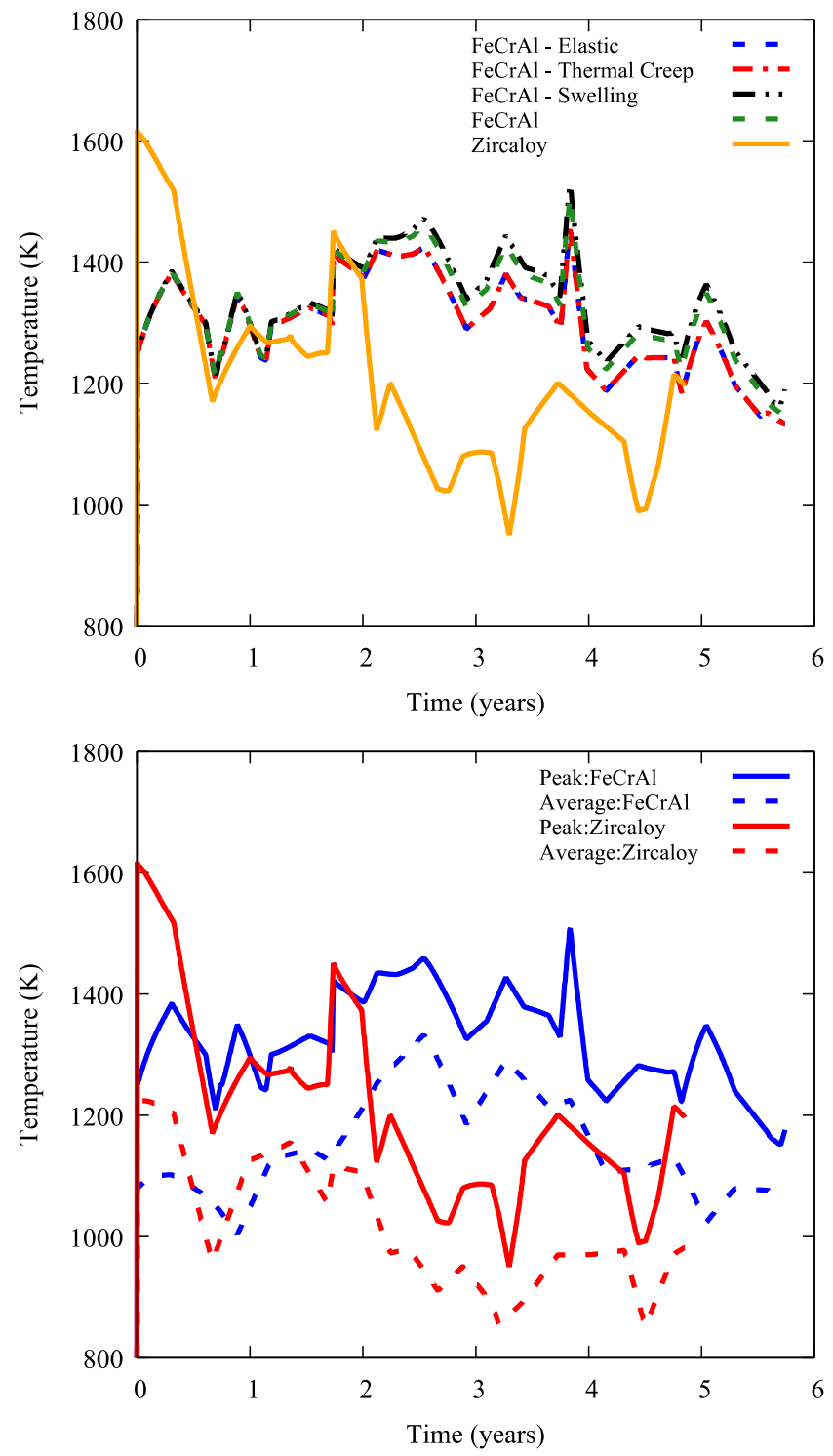

Figure 10. Peak and average fuel centerline temperatures for average-power operation conditions.

The dimensional change in the fuel rods is altered significantly by reducing the power produced by the fuel rods.

Figure 11 shows the axial elongation and the maximum radial displacement for the cladding during average-power operation. The immediate increase in axial elongation for all rods is due to thermal expansion of the cladding during the rise to operating temperature. Much like the FeCrAl cladded rods in the Limiting-Power operation, irradiation swelling has a substantial effect on cladding elongation. However, the FeCrAl-cladded rods do not achieve fuel-clad mechanical contact until late in life; the cladding is allowed to elongate without reductions due to radial expansion. The onset of fuel-clad mechanical interaction is delayed because the fuel swells, and thermally expands much less in this mode of operation. This is expected behavior as the swelling model is sensitive to fuel temperatures. The Zircaloy-cladded fuel rod also exhibits similar axial elongation characteristics to the Limiting-Power companion. Axial growth allows the fuel rods to expand axially, until mechanical contact occurs. 
With less fuel expansion, it follows that there is also less radial expansion in the cladding. The plot on the right shows the radial displacement of the cladding over its life. The initial deformation in the cladding is due to the thermal expansion during the rise to power. The FeCrAl-cladded rods without swelling, the cladding with elastic properties and thermal creep only, undergo no significant change in the cladding radius until gap closure. The rods that include the swelling model, however quickly begin to expand as the cladding swells isotropically. This acts to increase the fuel rod gap thickness and subsequently delays gap closure. There is a small effect from irradiation creep. Irradiation creep acts to help relieve stress by collapsing the cladding down around the fuel, contributing to a decrease in the cladding size. Effects from irradiation growth largely dominate radial deformation of Zircaloy cladding during this mode of operation. After the initial thermal expansion in the cladding, the cladding radius continues to decrease due to anisotropic irradiation growth and cladding creep-down until gap closure.
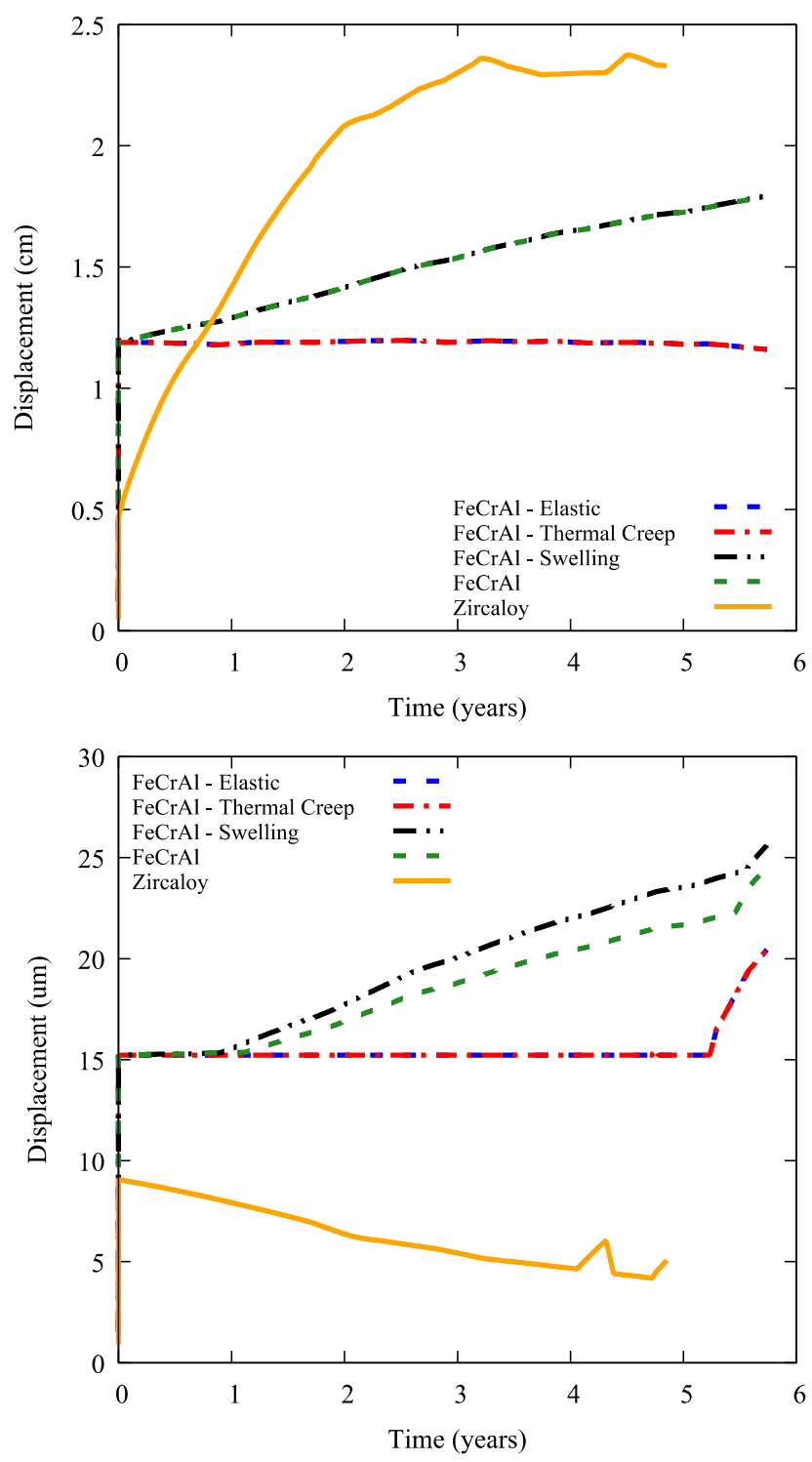

Figure 11. Axial elongation and maximum radial displacement of the cladding. 
Figure 12 shows the maximum cladding hoop stress that develops during average power operation. The cladding hoop stress is initially in a compressive state due to the pressure differential between the coolant system and the fuel rod plenum. In the FeCrAl-cladded rods, there is a very slight reduction in the hoop stress due to the increase in plenum pressure from fission gas release. Because fission gas release is greater in fuel rods with cladding swelling, a small reduction in the compressive hoop stress can be can be perceived, starting at approximately 2 years. Much of the fluctuation in the cladding stresses appears because of the variation in the axial power profiles during operation. At approximately 4.5 years, gap closure and subsequent cladding deformation occur in the FeCrAl-cladding rods without the irradiationswelling model. This occurs because a hot spot in the axial power profile enhances local fuel expansion producing an increase in hoop stress as the fuel pushes on the cladding. This interaction is short-lived, which results with the cladding stress returning to compressive hoop stresses determined by the differential pressure across the cladding. Gap closure occurs in these fuel rods slightly after 5 years, and hoop stresses in the cladding quickly increase immediately after onset. The FeCrAl-cladded rods that include swelling undergo gap closure nearly half a year later due to the associated cladding radial expansion. Gap closure behavior is significantly suppressed in the FeCrAl -cladded rods during average power operation. Here, it occurs much later at $\sim 5$ years, as opposed to $\sim 2$ years during the LimitingPower operation. The maximum cladding hoop stress at the end of life is also reduced when compared with the Limiting-Power operation because the radial deformation of the cladding is is much smaller.

The Zircaloy-cladded rod develops a much lower initial hoop stress because it has twice the cladding thickness of the FeCrAl-cladded rod. This means nearly half the compressive stress should develop in the cladding from the pressure differential. The cladding hoop stress remains in this state until gap closure occurs slightly after one year of operation. This is very similar to the behavior seen during the LimitingPower operation. Because the thermal creep rate will remain comparable and the irradiation creep rate will scale with the power, cladding creep-down occurs at a similar rate. The hoop stress after mechanical contact occurs in the Zircaloy-cladded fuel rod also fluctuates as the axial power profile influences radial expansion in the fuel.

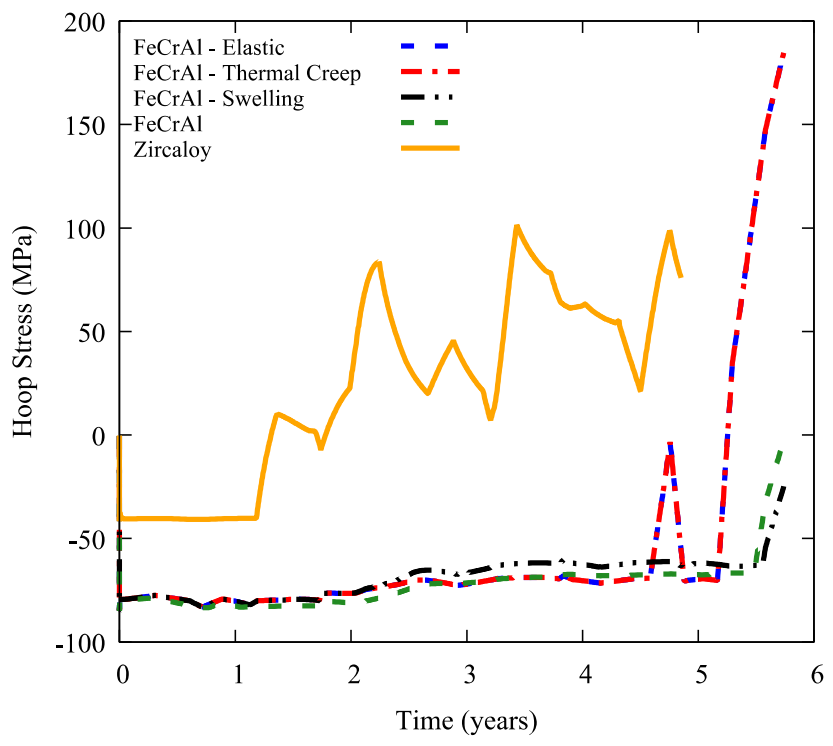

Figure 12. Maximum cladding hoop stress. 
The fission gas production in the fuel and release to the plenum during average-power operation are shown on the left and right, respectively, in Figure 13. As expected, the fission gas generated in the fuel during the average-power operation is scaled by $80 \%$ with the limiting-power operation. Because the power produced is the same for all of the FeCrAl-cladded fuel rods, the curves line up exactly.

As a result of the high fuel temperatures the Zircaloy-cladded rod experiences at the beginning of life, fission gas release begins immediately. The percentage of fission gas released increases to a peak at nearly $1.2 \%$ and tapers off as more fission gas generated in the fuel. This is similar behavior, while decreased in magnitude, to the Limiting-Power operation. The FeCrAl-cladded fuel rods do not release any fission gas until the second year. Here, fission gas release begins to rapidly increase as the fuel temperature begins to increase. There is a large effect due to the inclusion of the irradiation swelling and irradiation creep models. Irradiation swelling acts to expand the cladding and increase the gap thickness, which impedes heat-transfer from the fuel to the cladding. This increase in fuel temperature subsequently increases the fission gas release. Irradiation creep counteracts this by allowing the cladding to creep-down and decrease the gap thickness.

At the end of life in this mode of operation, the FeCrAl-cladded rods release $\sim 2$ - 5\% of gas generated, compared to $\sim 10-13 \%$ during the Limiting-Power operation. As a result of the lower fuel temperatures for much of the later life, the Zircaloy-cladded fuel rod releases much less fission gas that its FeCrAlcladded companion. 

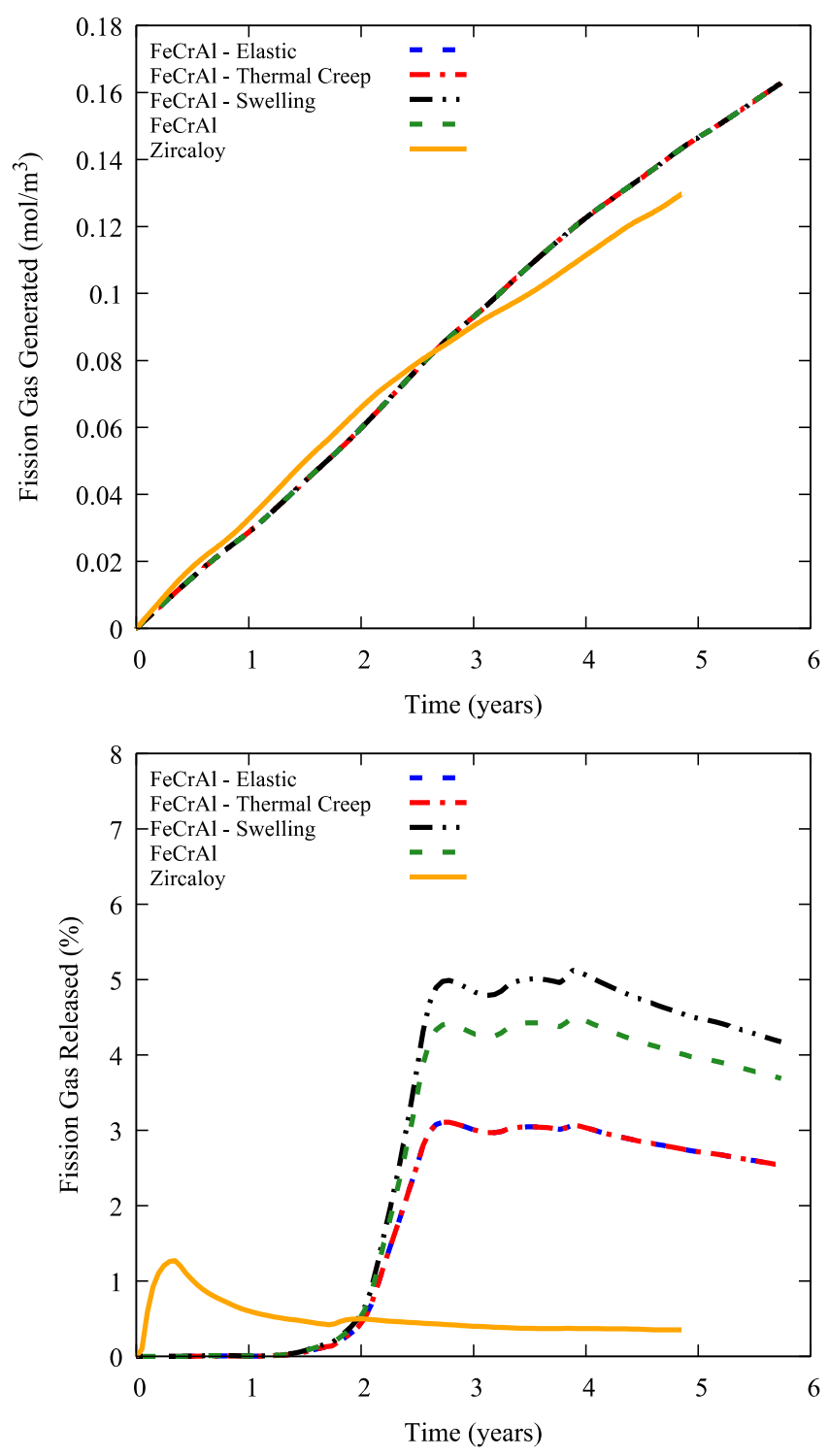

Figure 13. Fission gas generation in the fuel and release to the plenum.

Fuel rod plenum pressure and plenum volume are shown in Figure 14. The initial fill-gas pressure for these rods is set at .5 MPa, which quickly increases as the fuel rod heats to operating temperature. After the initial ramp to power, the plenum pressure for the FeCrAl-cladded fuel rods remains relatively unchanged until fission gas release occurs just after two years of operation. Because the plenum pressure is sensitive to the amount of gas present, features from the amount of fission gas released can be seen clearly in the plot of plenum pressure.

After the sharp increase, plenum pressure slowly increases as fission gas release slows. Because the contribution of the fission gas to the plenum pressure in the Zircaloy-cladded fuel rods is relatively insignificant, changes in the plenum pressure show similar features to the plenum volume. 

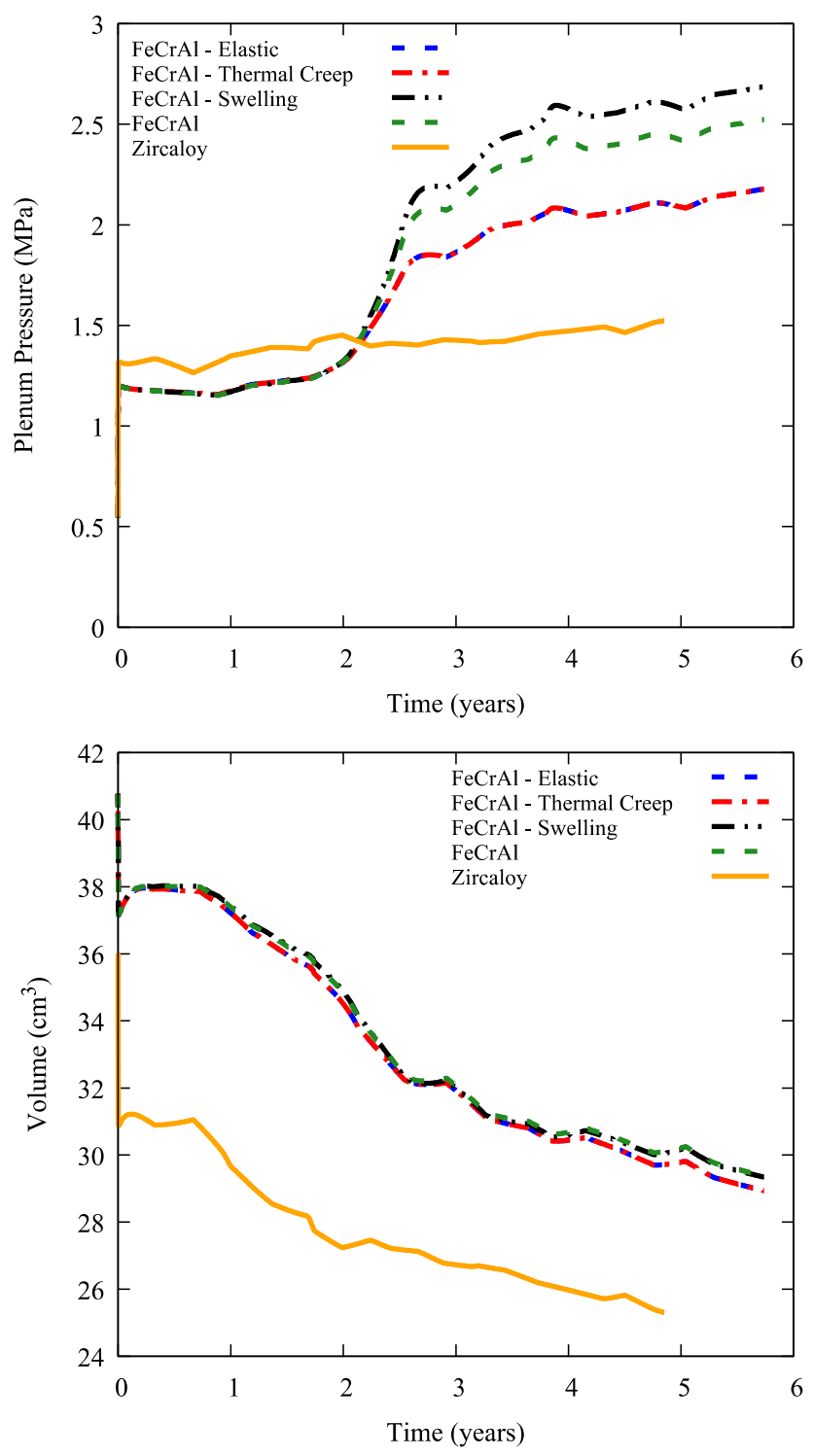

Figure 14. Fuel rod internal plenum pressure and plenum volume. 


\subsection{SIMPLIFIED POWER OPERATION}

For this analysis, the fuel rods were ramped to a linear heat rate of $18 \mathrm{~kW} / \mathrm{m}$ and held at this power to a rod average burnup of $60 \mathrm{MWd} / \mathrm{kgU}$. This operation is performed to allow much easier investigation of the integral and coupled behavioral evolution of the fuel rods.

Figure 15 displays a comparison between the peak fuel centerline temperatures between all five of the fuel rods and a comparison of the average fuel centerline temperatures of the full FeCrAl-cladded rod and Zircaloy-cladded rod.

The fuel temperatures initially increase from room temperature as the rod heats to operating power. Fuel temperatures in the FeCrAl-cladded rods begin to increase as the fuel thermal conductivity begins degradation. This also affects the Zry-cladded fuel rods, but reduction of the gap region due to creep deformation in the cladding acts to counteract this. Because the FeCrAl has very little creep deformation, the gap thickness between the fuel and cladding is largely dictated by fuel displacement. Figure 15 shows a significant temperature increase for the FeCrAl-cladded rods that include irradiation swelling, and a much small reduction in temperature from the inclusion of irradiation creep. This is due to the increased gap size that develops as the cladding diameter increases from irradiation swelling. The simulation including the irradiation creep shows counteracting gap closure. These effects can also be seen for the maximum radial displacement Figure 16.

At approximately $20 \mathrm{MWd} / \mathrm{kgU}$, fission gas release from the fuel begins to degrade the gap conductivity, and the fuel temperatures begin to increase faster. The temperatures reach a maximum near 35 $\mathrm{MWd} / \mathrm{kgU}$, where fuel expansion closes the gap enough to counteract the effects of fission gas release. The maximum temperatures decrease as the fuel and cladding undergo mechanical interaction along the rod beginning at $\sim 45 \mathrm{MWd} / \mathrm{kgU}$. The final increase in temperature at the end of the simulation is a result of the degraded thermal conductivity of the fuel and the poor gap conductivity where gap closure has not occurred.

The difference among curves in the FeCrAl-cladded rods is due to the irradiation-induced swelling in the cladding. By increasing the diameter of the cladding, swelling impeded heat transfer from the fuel to the cladding. This causes increased temperatures, which contributes to greater fission gas release.

The Zircaloy cladding behaves much differently. After the initial power ramp, the cladding begins to creep toward the fuel due to the pressure differential between the rod fill gas pressure and the reactor coolant pressure. This allows gap closure to occur much sooner than the FeCrAl rods at approximately 25 $\mathrm{MWd} / \mathrm{kgU}$. Because the Zircaloy contains less fuel mass, the rod burn-up increases faster. This causes the thermal conductivity of the fuel in the Zircaloy to degrade faster, seen here after $\sim 25 \mathrm{MWd} / \mathrm{kgU}$. In this case, lower fuel temperatures allow the onset of large-scale fission gas release from the fuel to occur later and contribute little to temperature changes in the Zircaloy-cladded fuel rod. 

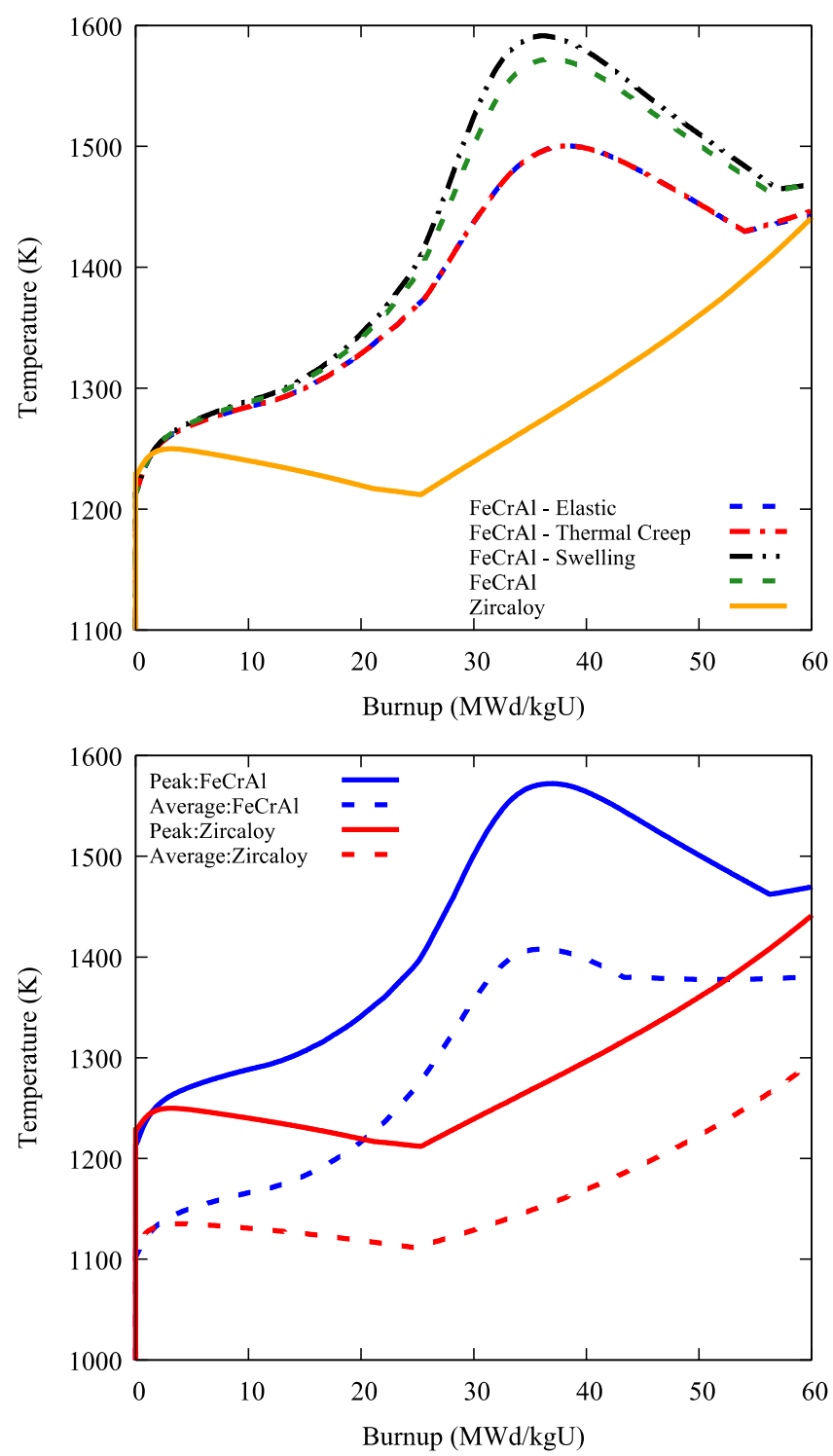

Figure 15. Peak and Average fuel centerline temperatures.

The axial elongation and radial displacement of the fuel rod cladding under simplified operation are shown in Figure 16.

After the initial thermal expansion, the FeCrAl cladding shows very clear elongation due to irradiation swelling in the cladding, even after mechanical contact has occurred. Zircaloy shows a similar trend due to irradiation growth, where the cladding elongates until significant fuel-cladding mechanical contact begins to increase the fuel radius, counteracting the axial elongation due to Poisson's effect. The FeCrAlcladded fuel rods that do not include irradiation swelling remain essentially the same length until mechanical interaction occurs.

The FeCrAl-cladded fuel rods modeled with irradiation swelling also show much more radial expansion. FeCrAl-cladded rods without irradiation swelling simply remain the same radius after initial thermal 
expansion until mechanical interaction. Zircaloy-cladded rods, as mentioned previously, experience orders of magnitude more creep than FeCrAl-cladding. This allows the Zircaloy-cladding to slowly collapse around the fuel due to the pressure differential between the plenum pressure and the reactor coolant pressure. It is worth noting again that, in the Zircaloy-cladded rod, gap closure occurs before the sharp increase in radial displacement because the cladding tube wall near the ends does not creep down as much as the other areas. This is due to the additional structure that the cladding end caps provide.
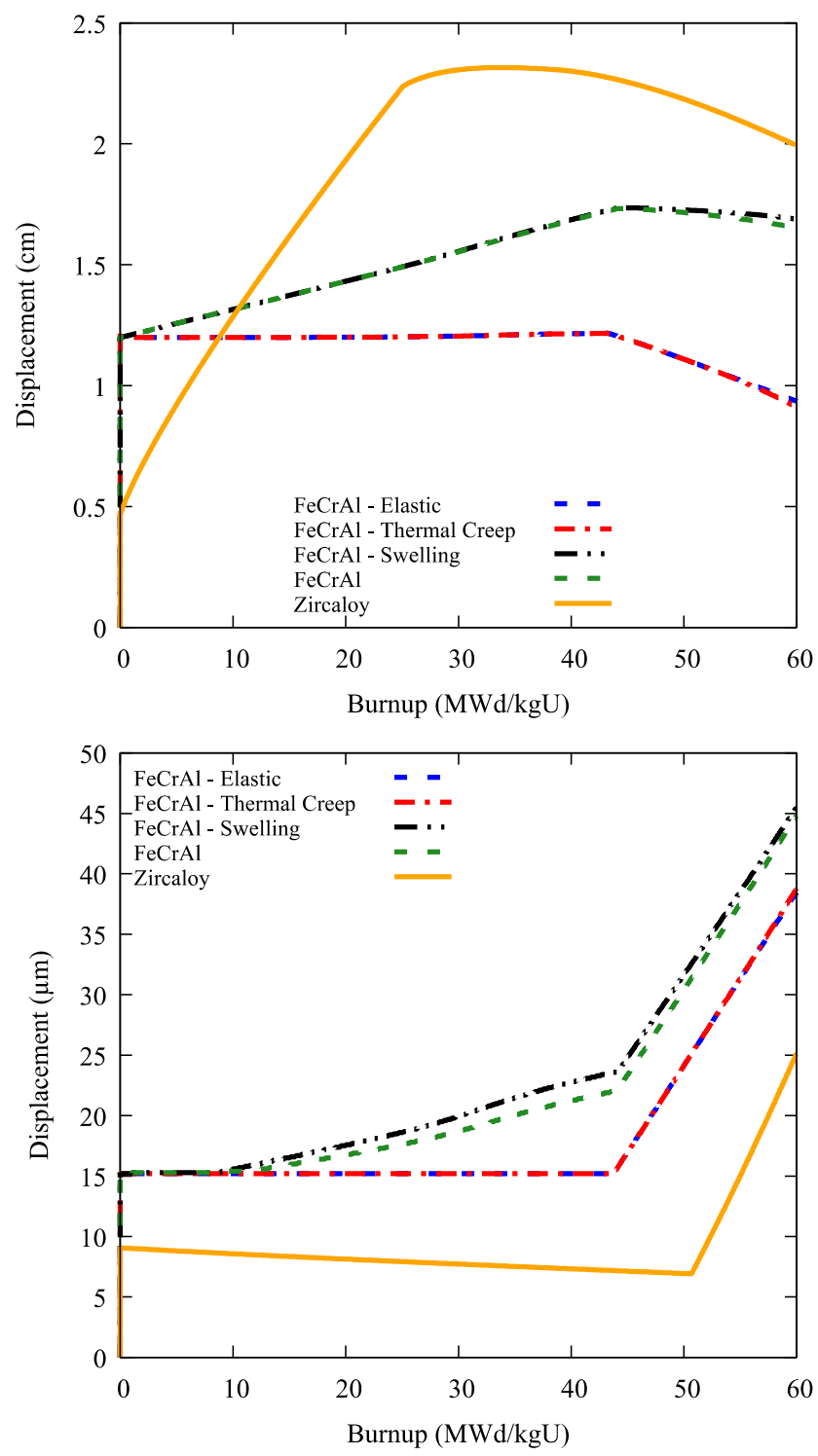

Figure 16. Axial elongation and maximum radial displacement of the cladding.

The maximum hoop stress, shown in Figure 17, as with the other operational cases, remains compressive due to the pressure differential across the cladding until gap closure. It shows a small reduction in compressive hoop stress due to an increase in plenum pressure as fission gas is released beginning at 25 $\mathrm{MWd} / \mathrm{kgU}$. After gap closure occurs, the hoop stresses quickly become tensile as the fuel starts expanding the cladding. 
Much like the other modes of operation, the hoop stress in the FeCrAl cladding rapidly increases after the onset of gap closure. Figure 17 shows the effects of including each of the FeCrAl material models and the difference in stress reduction between Zircaloy and FeCrAl. At the end of the simulation, slight stress relaxation from irradiation creep can be observed. Just as the previous operational modes showed, the Zircaloy-cladded rod undergoes mechanical contact much sooner than the FeCrAl-cladded rods ( 20 $\mathrm{MWd} / \mathrm{kgU}$ earlier) and the maximum hoop stress also saturates at a much lower value. For the Zircaloycladded fuel rod, gap closure occurs before fission gas release becomes prominent.

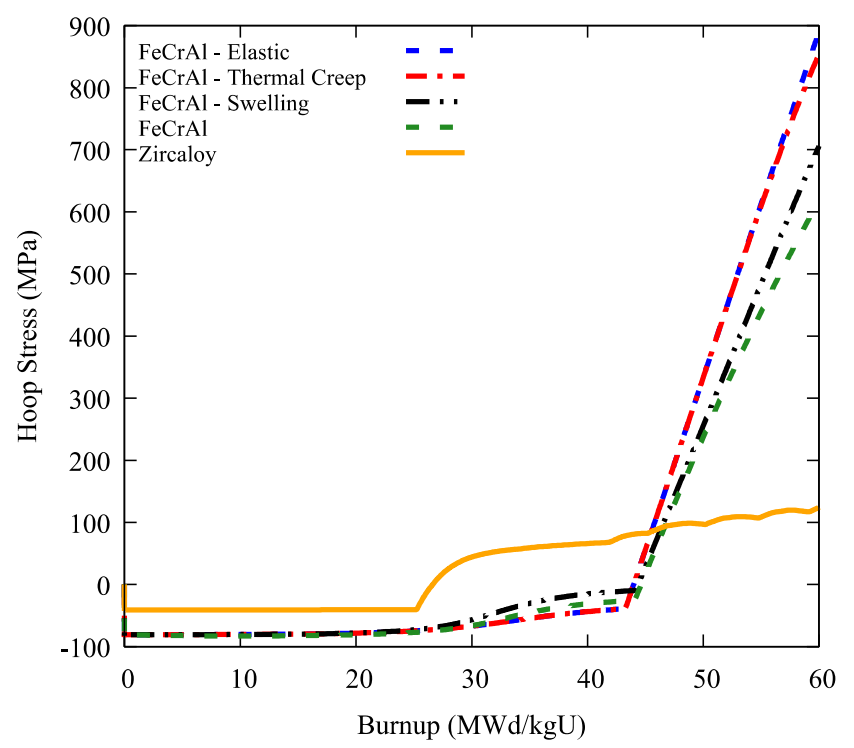

Figure 17. Maximum cladding hoop stress.

The fission gas generated for both cladding types is shown in the left plot of Figure 18, and the corresponding plenum volumes are shown in Figure 19. The amount of fission gas released is heavily temperature dependent, and therefore varies greatly, even among FeCrAl cladded fuel rods. This is largely a function of the higher fuel temperatures in the FeCrAl clad fuel, due to the increase in fuel pellet dimension to offset the neutronics penalty associated with the clad. However, we believe that the fission gas release model is another material property that requires further evaluation in this analysis. 

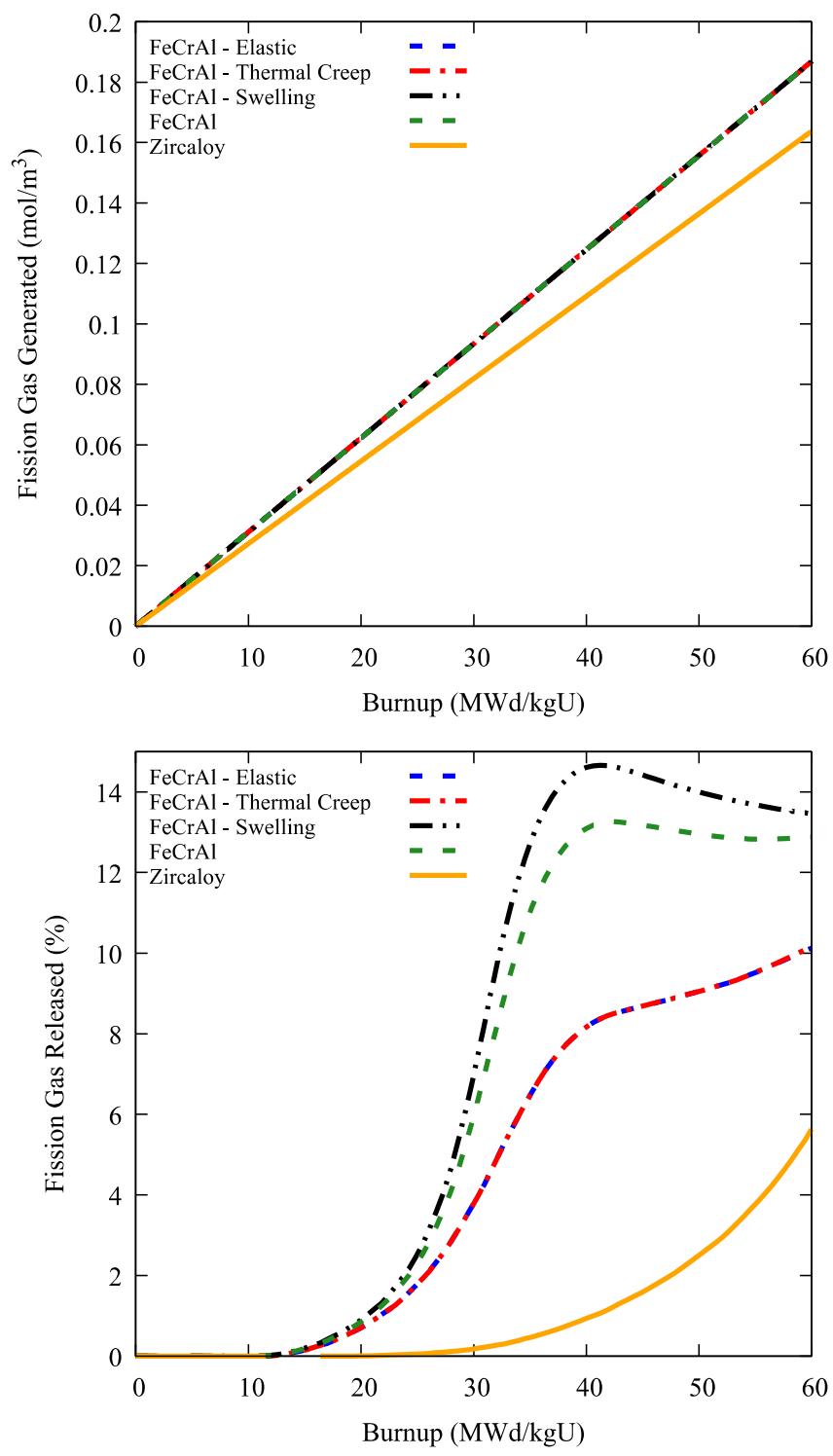

Figure 18. Fission gas generated in the fuel (left) and percent of fission gas released to the fuel plenum (right). 

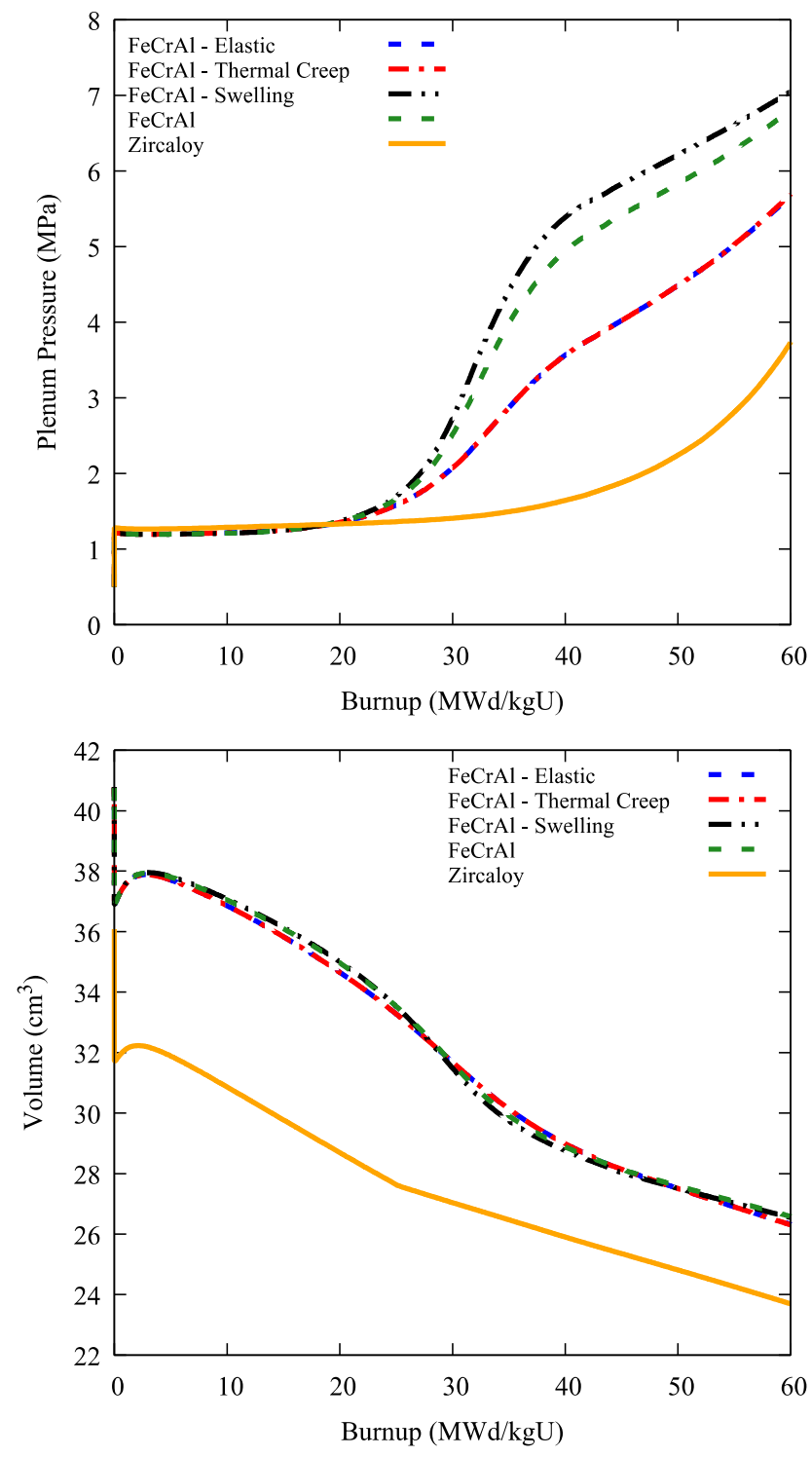

Figure 19. Fuel rod internal plenum pressure and plenum volume. 


\subsection{CLADDING THERMAL AND IRRADIATION CREEP ANALYSIS}

During the initial analysis, it was determined that the hoop stresses forming in the FeCrAl cladding were prohibitively large for normal operation. This was determined to arise due to a lack of compliance in both the fuel and cladding materials. Because stress-relief mechanisms, such as smeared cracking, were not currently implemented for fuel, which is known to fracture during the rise to power, constitutive models for fuel thermal and irradiation creep were not considered.

In order to mitigate these large stresses, cladding compliance was analyzed through variation of thermal and irradiation creep models. Based on the results of the operational analysis and the belief that the thermal creep rate model used was conservative, it was suggested to identify what creep rates would be necessary to significantly reduce the maximum hoop stresses formed in the FeCrAl cladding.

In order to perform this analysis, a series of nearly identical simulations were run to identify effects of varying parameters from the irradiation (equation 3) and thermal (equation 4) creep rates. The irradiation creep prefactor was varied along with the thermal creep pre-exponential and activation energy.

The simulations performed used the same operational parameters as Section 3.3 (simple axial power profile and constant $18 \mathrm{~kW} / \mathrm{m}$ linear heat rate), as well as the same geometry used for all FeCrAl-cladded fuel simulations.

Figure 20 shows two contour plots of the maximum cladding hoop stresses at the end of the fuel rod operation as a function of the thermal creep activation energy and pre-exponential terms. The plots are varied by the irradiation creep prefactor used. The plot on the left uses the same prefactor used in previous analysis $\left(.5 \times 10^{-6} \mathrm{MPa}^{-1}-\mathrm{dpa}^{-1}\right)$, while the plot on the right uses the prefactor increased by an order of magnitude $\left(.5 \times 10^{-5} \mathrm{MPa}^{-1}-\mathrm{dpa}^{-1}\right)$. 

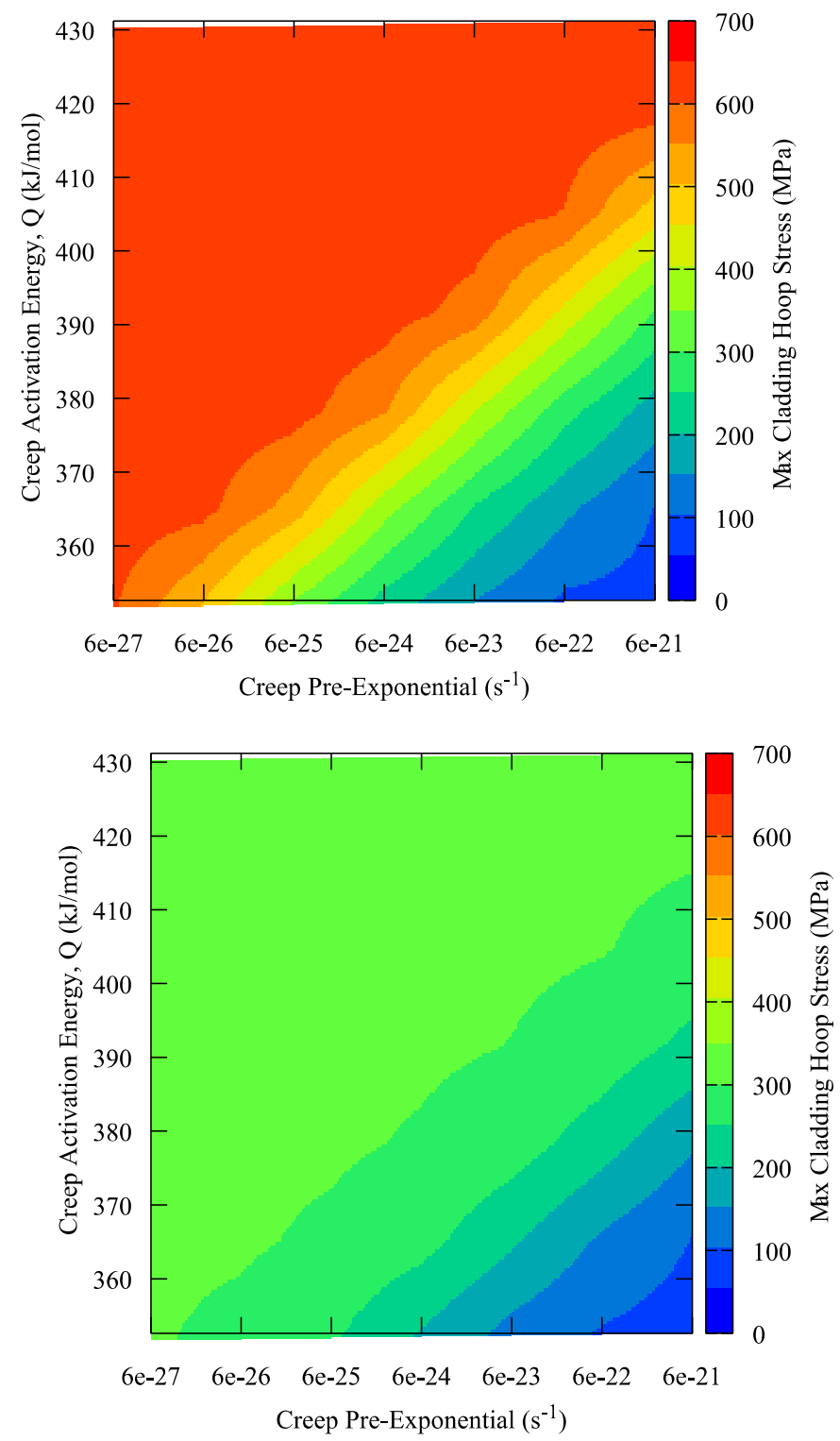

Figure 20. Contour plots of maximum cladding hoop stress as a function of thermal creep preexponential and activation energy for irradiation creep pre-factor of .5 $\times 10^{-6}$ (left) and $.5 \times 10^{-5}$ (right).

The results shown in Figure 20 indicate that the current thermal and irradiation creep model is just out of regime where stress is relieved. Significant changes to the irradiation creep develop extremely large changes in the stress contours, regardless of thermal creep model. Informing alloy designers of both small improvements in both allows large stresses to be reduced. Important for accident or high power scenarios where fuel swells rapidly. Cladding without creep deformation will rely on fuel compliance during mechanical contact events. Thus, we have next turned to a more systematic analysis of the impact of fuel creep on the resulting FeCrAl clad stresses. 


\subsection{FUEL CREEP ANALYSIS}

During the course of this study, it was determined that the there may be uncertainty in the models used to simulate the fuel compliance and a reexamination was performed to identify effects of using fuel creep models implemented in BISON.

A parametric study was performed to determine how neglecting creep deformation in the fuel would influence the cladding deformation and stress state. In the previous analyses, the fuel was modeled without thermal and irradiation creep, as fracture models were not implemented. This assumption was motivated by the expectation that fuel creep would be greatly over-predicted without modeling fracture. In this section, the fuel creep rate model is varied in order to determine the impact of this assumption on the cladding deformation and stress state. This analysis was performed using the same models as Sections 3.3 and 3.4. However, for this analysis, a scale factor was added to the fuel creep rate model. The fuel was simulated at a constant linear heat rate of $18 \mathrm{~kW} / \mathrm{m}$ to a rod average burnup of $60 \mathrm{MW}-\mathrm{d} / \mathrm{kgU}$.

Figure 21 shows the maximum fuel hoop stress and radial displacement over the fuel utilization. The scale factors used were varied by decades starting at $1 \times 10^{-4}$ and increasing to one, where the model is executed as originally implemented. The plot of the maximum hoop stress shows that, as expected, the fuel hoop stress continues to increase for the lowest scale factor, and each progressive increase in scale factor shows a more pronounced reduction in hoop stress. Using the model as implemented, the hoop stress initially increases due to thermal expansion, and then quickly reduces as the stress is quickly relieved.

The plot of the maximum radial displacement for the fuel shows a stark difference in behavior after mechanical contact has occurred at $\sim 42 \mathrm{MWd} / \mathrm{kgU}$. All reduced scale factors show expansion of the fuel deforming the cladding by nearly 20 microns after contact. By not scaling the creep rate, the fuel only expands a small amount, limited by the stiffness of the cladding. 

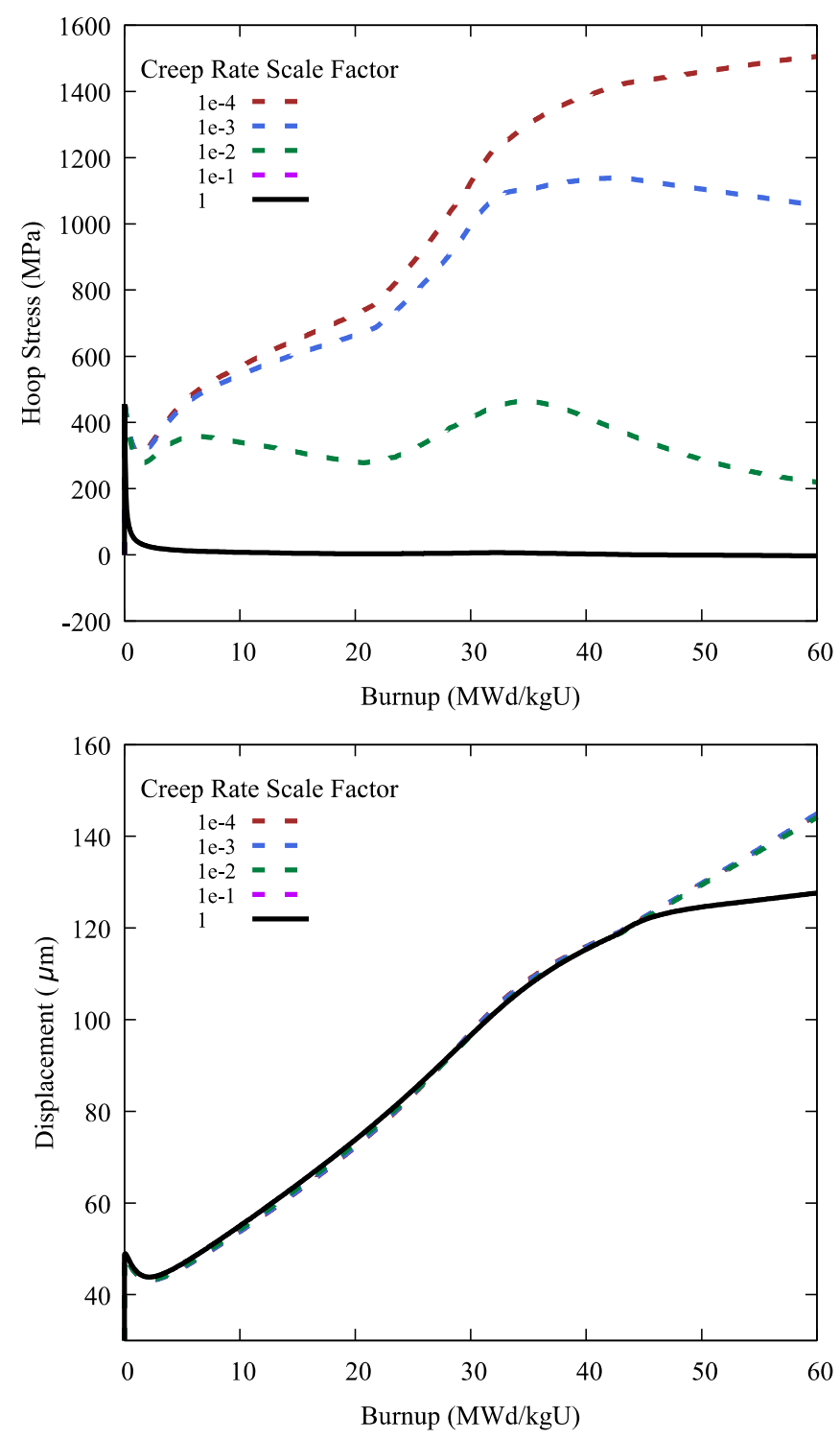

Figure 21. Maximum hoop stress and radial displacement of the fuel over the simulation time.

This shows that the cladding behavior is also greatly affected by scaling the fuel creep rate model. Figure 21 shows the maximum hoop stress and radial displacement for the cladding over the simulation. In this plot, there is almost no discernable effect between the reduced scale factors. However, by using the model as implemented, the hoop stresses decrease from nearly $650 \mathrm{MPa}$ to approximately $100 \mathrm{MPa}$. The radial deformation of the cladding due to fuel expansion is also greatly reduced $(\sim 15 \mu \mathrm{m})$. 

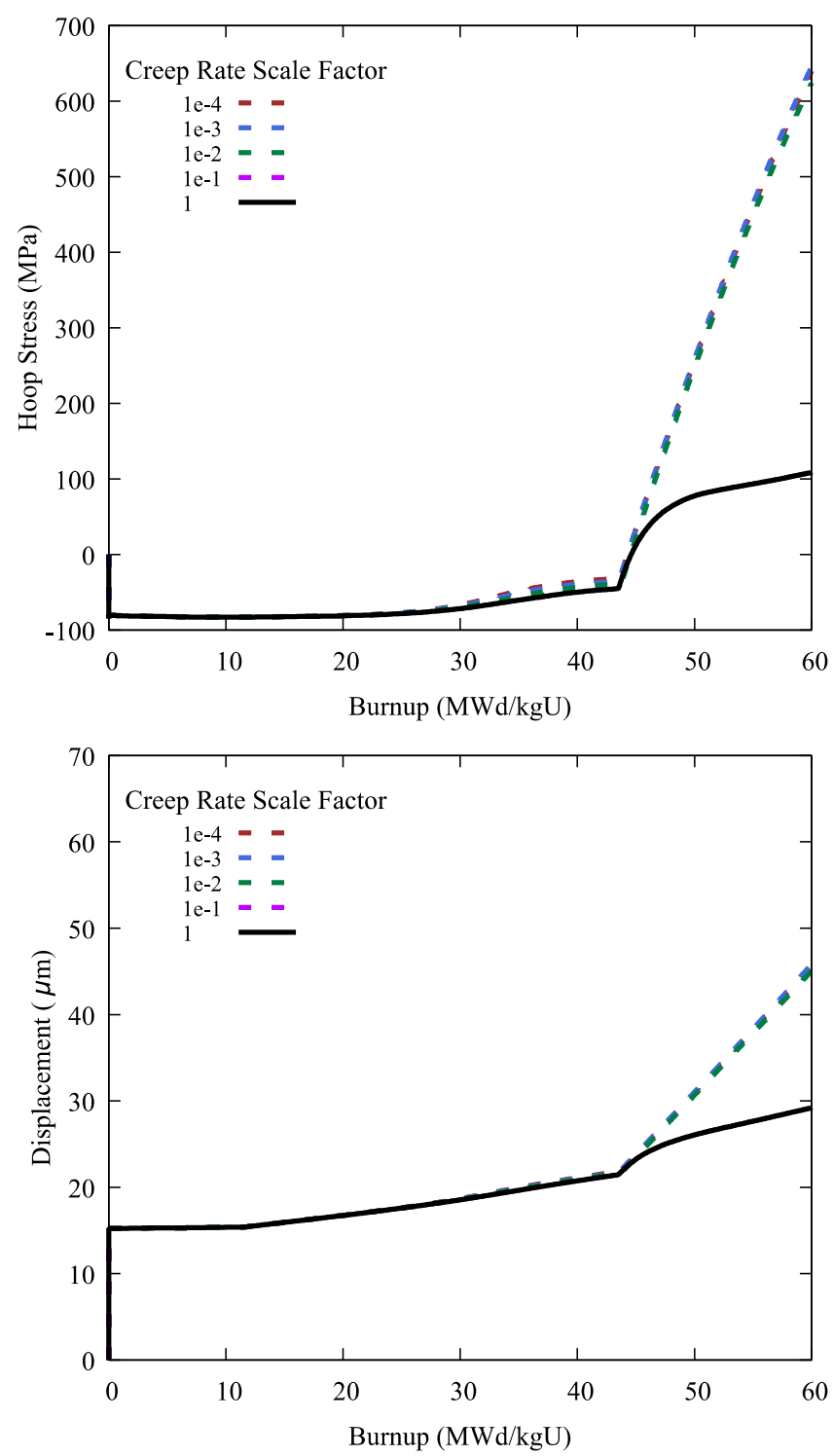

Figure 22. Maximum cladding stress and radial displacement of the fuel over the simulation time.

These results again show that, while the focus has been on developing cladding behavioral models, fully developing fuel constitutive models is necessary to predict cladding behavior after mechanical contact has occurred. While fuel creep in this operations does not change the time for gap closure to occur, it greatly changes the cladding and fuel response afterwards. 


\section{SUMMARY}

The work presented herein focused on the thermo-mechanical analysis of FeCrAl cladding which is considered a leading candidate for accident tolerant fuel cladding systems in light water reactors. The results from the analysis showed the development of high tensile stresses in the cladding across several different BWR operational scenarios. However, the Large changes in the results can arise from small shifts in data and are due to the complex, coupled sensitivities inherent in integral fuel performance modeling.

While these simulations show very large stresses (>600 MPa) forming the in the FeCrAl cladding (much larger than the yield strength at these temperatures), they do provide information on important parameters for alloy design and certain modeling techniques. Due to limitation and uncertainty in modeling fuel creep and stress relief mechanisms, such as cracking, fuel creep is not modeled in these simulations. It is, however, expected to play a large role in the stress evolution of the FeCrAl cladding. Modeling fuel creep and further detail in FeCrAl behavioral models is essential in accurately determining integral fuel performance of FeCrAl-cladded fuel rods.

Future efforts will focus on continuing the systematic evaluation of $\mathrm{FeCrAl}$ and $\mathrm{UO}_{2}$ thermal-mechanical constitutive properties and irradiation behavior models, including against experimental data being developed within the FCRD program, and initiating the modeling investigation of transient fuel clad behavior.

\section{REFERENCES}

Franklin, D. (1982). Zircaloy-4 cladding deformation during power reactor irradiation Zirconium in the Nuclear Industry: ASTM International.

Garner, F. A., Toloczko, M. B., \& Sencer, B. H. (2000). Comparison of swelling and irradiation creep behavior of fcc-austenitic and bcc-ferritic/martensitic alloys at high neutron exposure. Journal of Nuclear Materials, 276, 123-142. doi:Doi 10.1016/S00223115(99)00225-1

Gaston, D., Newman, C., Hansen, G., \& Lebrun-Grandie, D. (2009). MOOSE: A parallel computational framework for coupled systems of nonlinear equations. Nuclear Engineering and Design, 239(10), 1768-1778.

George, N. M., Powers, J. J., Maldonado, G. I., Worrall, A., \& Terrani, K. A. (2015). Development of a Full-core Reactivity Equivalence for FeCrAl Enhanced Accident Tolerant Fuel in BWRs. Retrieved from

Hagrman, D. T., Allison, C. M., \& Berna, G. A. (1995). SCDAP/RELAP5/MOD 3.1 code manual: MATPRO, A library of materials properties for Light-Water-Reactor accident analysis. Volume 4 (NUREG/CR--6150-Vol.4; EGG--2720-Vol.4; ). Retrieved from http://www.osti.gov/scitech//servlets/purl/100327/

Hales, J., Novascone, S., Pastore, G., Perez, D., Spencer, B., \& Williamson, R. (2014). BISON theory manual: The equations behind nuclear fuel analysis: Fuels Modeling \& Simulation Department, Idaho National Laboratory, Idaho Falls, Idaho.

Heinisch, H. L., Greenwood, L. R., Weber, W. J., \& Williford, R. E. (2004). Displacement damage in silicon carbide irradiated in fission reactors. Journal of Nuclear Materials, 327(2), 175-181. 
Hofmann, P. (1998). Current knowledge of core degradation phenomena, a review. Journal of Nuclear Materials, 270, 194-211.

Kanthal Alkrothal 720 Datasheet. Hallstahammar, Sweden: Sandvik AB.

Kanthal APMT Datasheet. Hallstahammar, Sweden: Sandvik AB.

Larsen, N. H. (1978). Core design and operating data for Cycles 1 and 2 of Peach Bottom 2 (EPRI-NP-563; TRN: 79-001822 United States10.2172/6561294TRN: 79-001822Tue Mar 10 05:24:05 EDT 2015Dep. NTIS, PC A10/MF A01.GE; ERA-04-013231; EDB-79018562English). Retrieved from http://www.osti.gov/scitech//servlets/purl/6561294/

Lassmann, K. (1980). The Structure of Fuel-Element Codes. Nuclear Engineering and Design, 57(1), 17-39. doi:Doi 10.1016/0029-5493(80)90221-6

Limbäck, M., \& Andersson, T. (1996). A model for analysis of the effect of final annealing on the in-and out-of-reactor creep behavior of zircaloy cladding. Paper presented at the Zirconium in the Nuclear Industry: Eleventh International Symposium.

Moore, R., \& Notz, K. (1989). Physical characteristics of GE BWR fuel assemblies. ORNL/TM10902 (2nd ed.) Oak Ridge National Laboratory, Oak Ridge, TN.

OECD. Nuclear Fuel Safety Criteria Technical Review (Second Edition): OECD Publishing.

Olander, D. R. (1976). Fundamental aspects of nuclear reactor fuel elements. Retrieved from

Rashid, Y., Dunham, R., \& Montgomery, R. (2004). Fuel analysis and licensing code: FALCON MOD01. EPRI Report, 1011308.

Saunders, S. R. J., Evans, H. E., Li, M., Gohil, D. D., \& Osgerby, S. (1997). Oxidation growth stresses in an alumina-forming ferritic steel measured by creep deflection. Oxidation of Metals, 48(3-4), 189-200. doi:Doi 10.1007/Bf01670498

Terrani, K. A., Karlsen, T.M., Yamamoto, Y. (2015). Report on Design and Preliminary Data of Halden In-Pile Creep Rig, ORNL/TM-2015/507. Retrieved from Oak Ridge National Laboratory:

Terrani, K. A., Zinkle, S. J., Snead, L. L. (2014). Advanced oxidation-resistant iron-based alloys for LWR fuel cladding. Journal of Nuclear Materials, 448(1-3), 420-435. doi:10.1016/j.jnucmat.2013.06.041

Williamson, R. L., Hales, J. D., Novascone, S. R., Tonks, M. R., Gaston, D. R., Permann, C. J., . . Martineau, R. C. (2012). Multidimensional multiphysics simulation of nuclear fuel behavior. Journal of Nuclear Materials, 423(1-3), 149-163. doi:10.1016/j.jnucmat.2012.01.012 